\title{
COMPARATIVE ASSESSMENT OF NONLINEAR STATIC AND DYNAMIC METHODS FOR ANALYSING BUILDING RESPONSE UNDER SEQUENTIAL EARTHQUAKE AND TSUNAMI
}

\author{
Tiziana ROSSETTO ${ }^{1}$, Camilo DE LA BARRA ${ }^{2}$, Crescenzo PETRONE $^{3}$, Juan Carlos DE LA LLERA ${ }^{4}$, Jorge \\ VASQUEZ $^{5}$, Marco BAIGUERA ${ }^{6}$
}

\begin{abstract}
This paper presents a comprehensive comparison of different dynamic and static approaches for assessing building performance under sequential earthquakes and tsunami. A 10-storey reinforced concrete seismically designed Japanese vertical evacuation structure is adopted as a case study for the investigation. The case study building is first assessed under sequential earthquake and tsunami non-linear response history analyses: the first time this is done in the literature. The resulting engineering demand parameters are then compared to those obtained when the analysis procedure is systematically simplified by substituting different static approaches for the nonlinear response history analyses in both the earthquake and tsunami loading phases. Different unloading approaches are also tested for the cases when an earthquake pushover is adopted. The results show that an earthquake nonlinear response history analysis, followed by a transient free vibration and a tsunami variable depth pushover provide the best alternative to full dynamic analyses in terms of accuracy and computational efficiency. This structural analysis combination is recommended, and has the advantage that it does not require the tsunami inundation time history to be known in advance. The proposed double pushover approach is instead deemed only suitable for the collapse assessment of regular low to mid-rise buildings and for the development of collapse fragility functions. An important observation made is that sustained earthquake damage, seems not to affect the tsunami resistance of the case study building when the fully dynamic analysis is carried out for the sequential loading. This observation will be the subject of future work.
\end{abstract}

Keywords: Tsunami engineering, Tsunami force, Pushover Analysis, Response-History Analysis, Sequential Earthquake and Tsunami.

\section{INTRODUCTION}

Recent earthquake-triggered tsunami, such as the 2011 Great East Japan event or the 2010 Maule tsunami in Chile, have resulted in extensive damage to coastal infrastructure and substantial economic losses (e.g. [1], [2] and [3]) . Much of these losses were sustained along coastlines that were affected firstly by the earthquake ground shaking and then by the tsunami inundation. From a disaster management perspective, risk assessment tools that can be adopted in the prediction of the impact of cascading earthquakes and tsunamis are crucial for improving the disaster resilience of coastal infrastructure susceptible to these hazards. Though significant advances have been made in the modelling of the earthquake and tsunami hazards (e.g. [4], [5]), few fragility functions exist for the estimation of the damage induced by these sequential events on coastal infrastructure. Empirical fragility functions have been developed from observations made of damaged buildings in locations affected both by earthquakes and subsequent tsunami (e.g. [6], [7] and [8]). These are commonly presented in the literature solely as tsunami fragility functions, the assumption being made that the preceding earthquake damage has little effect on the tsunami induced damage

${ }^{1}$ Professor, EPICentre, Department of Civil, Environmental and Geomatic Engineering, University College London, Gower Street, London,WC1E 6BT, United Kingdom, t.rossetto@ucl.ac.uk

${ }^{2}$ Research Assistant, EPICentre, Department of Civil, Environmental and Geomatic Engineering, UCL, UK.

${ }^{3}$ Earthquake Research Analysist, Willis Re, Willis Group Limited, 51 Lime Street $10^{\text {th }}$ Floor, London, EC3M 7DQ, UK

${ }^{4}$ Dean, School of Engineering and Professor, Department of Structural and Geotechnical Engineering, Pontificia Universidad Católica de Chile and National Research Center for Integrated Natural Disaster Management, Vicuña Mackenna 4860, Santiago, Chile.

${ }^{5}$ Researcher, Department of Structural and Geotechnical Engineering, Pontificia Universidad Católica de Chile, Vicuña Mackenna 4860, Santiago, Chile.

${ }^{6}$ Research Associate, EPICentre, Department of Civil, Environmental and Geomatic Engineering, UCL, UK. 
[9]. However, in post-tsunami damage surveys it is not usually possible to distinguish between earthquake and tsunami-related damage, and so it is difficult to assess whether this is actually the case. As discussed below, only few past studies have proposed structural analysis methods for investigating the process of building damage across these sequential hazards, and make significant assumptions in order to reduce computational expense. This paper therefore presents a comprehensive comparison of different approaches for assessing the structural performance of buildings under sequential earthquakes and tsunami. It aims to assess the effect of analysis method simplification and of analysis implementation assumptions on the predicted structural response, and proposes a new doublepushover approach for use in the fragility assessment of low- to mid- rise regular structures.

In earthquake engineering the seismic performance assessment of structures through numerical analysis is well established, with a number of available approaches with differing complexity and accuracy. Some of the most commonly used are earthquake nonlinear response history analyses (denoted with the abbreviation DY in this paper) for complex, irregular or tall structures; and pushover analyses (denoted with abbreviation PO) for regular, low-to mid-rise structures. Instead, the assessment of structures under tsunami loading through numerical analysis is still in its infancy.

Significant past research has focussed on the characterisation of tsunami forces on buildings and infrastructure (e.g. [10] and [11], amongst others), whilst comparatively few studies have looked at structural analysis approaches under this loading. The latter have largely built upon traditional numerical analysis methods used in earthquake engineering, presenting modifications of these to account for the specific characteristics of the tsunami inundation. Amongst these are tsunami nonlinear response history analyses (TDY) and variable depth tsunami nonlinear pushover approach (VDPO), both proposed and adopted in [12], constant depth tsunami nonlinear pushover approaches (CDPO) (e.g. used in [12] and [13] ), and the application of statistically generated static forces of different sizes (e.g. used in [14] and [15]).

TDY follows the same principles as an earthquake DY. In TDY, a tsunami inundation depth $(h(t))$ and velocity $(u(t))$ time history is used to calculate a corresponding lateral force time history $\left(F_{T}(t)\right)$. At each time step of the response history analysis, the tsunami force is applied to the structure assuming a given load distribution up to the tsunami inundation depth at that time step, and the resulting structural response is computed.

In terms of pushover-based approaches, the CDPO method is the most similar to a conventional earthquake pushover analysis. In CDPO a constant tsunami inundation depth $(h)$ is considered, a lateral load pattern is applied to the structure over its height to $h$, and a displacement-controlled analysis carried out. By fixing the tsunami inundation depth, an increase in the nett lateral force essentially means an increase in the flow velocity $(u)$, resulting in a variation in the Froude number $\left(F_{r}\right)$ of the equivalent tsunami inundation throughout the analysis. In [14] and [15] the tsunami inundation depth and velocity are treated as independent variables, and pairs of values are randomly generated with limits posed on the resulting Froude numbers such that they are similar to a real tsunami. A static force is calculated from each $h$ - $u$ pair and applied to the structure over its height to $h$, according to a given lateral load pattern. In essence this approach can be considered similar to the generation of a series of CDPO for different target tsunami inundation depths, and hence is not further considered in this paper. Like CDPO, VDPO analyses apply lateral loads to the structure according to a given load distribution. However, in VDPO the tsunami inundation depth linearly increases up to a target value $h_{\max }$ (see Figure 1), whilst maintaining a constant Froude number. The height of the load pattern increases at each step of analysis, introducing new points of load application. VDPO is a force-controlled procedure, and hence is not able to capture the post-peak behaviour in the pushover curve (branch $D-E$ in the schematic tsunami pushover curve in Figure 1) [12]. However, [16] demonstrate that due to the typically long duration of tsunami inundation flows, only a very limited over-strength is achievable in structures for realistic values of ductility i.e. ductility cannot be relied upon for resisting loads much greater than the structure tsunami yield strength. Consequently, a pushover-based approach (even if not well-representing the post-peak behaviour) may be adequate for the assessment of the tsunami response of structures.

All the aforementioned approaches to tsunami analysis of structures must make an assumption regarding the shape of the applied lateral load distribution they use. As stated in [15], there is no consensus on this point, with experimental studies reporting either uniform or triangular lateral load distributions. In the analytical literature and current codes of practice, uniform lateral load distributions are adopted in [14], [15] and [17], whilst triangular and trapezoidal nett lateral load distributions are used in [12]. In these studies, the triangular distribution is assumed to simulate a hydrostatic-type loading, whilst the uniform or trapezoidal nett lateral load distributions are assumed to account for hydrodynamic loading with some balancing of tsunami loads at the front and back of buildings.

Very few studies that assess the structural behaviour of buildings under the sequential effect of earthquake and tsunami have been proposed. Among these, [18] develops fragility functions for a two-storey timber building 
subjected to successive earthquake and tsunami loading. They model the timber building as a single degree of freedom (SDoF) system, with strength and stiffness degradation characterised through the CUREE hysteretic response model [19]. In the first stage of the analysis, earthquake nonlinear response history analyses are carried out on the SDoF for 44 ground motions. The structural model is then checked for collapse via tsunami CDPO using a degraded backbone curve for the SDoF. In [18], the tsunami loading is determined as per the FEMA P-646 guidelines [20], and uncertainty in tsunami inundation depth is considered. A much more complex structural model and continuous time-based analysis is adopted by [21] in the assessment of a 7-storey reinforced concrete (RC) wall-frame structure under dynamic earthquake nonlinear response history analyses and subsequent tsunami CDPO. Both [18] and [21] report that the tsunami inundation depth required to collapse their assessed structures decreases when the ground motion intensity of the preceding earthquake increases. These observations would suggest that the earthquake damage has a significant effect on the tsunami resistance of the building. However, this observation cannot be concluded from these two studies alone, especially as both studies present limitations with regard to the representation of the tsunami loading. They only consider constant depth pushover (CDPO) analyses and use a coarse discretisation of the applied loading along the height of the building; feature which is shown to significantly affect the reliability of the tsunami pushover analysis results [12], (see also Section 5.0).

No past studies have as yet present a fully dynamic approach where a building is subjected to sequential nonlinear response history analyses for both the ground motion and the tsunami inundation, with a free vibration phase in between the two loading histories. Despite this approach likely being the most accurate approach for analysing a structure under these sequential hazards, it has not been used to date as it is complex and can be associated with large computation times depending on the model complexity and material type of the building [22]. Sequential earthquake and tsunami nonlinear response history analyses pose a substantial computational burden. Therefore, although appropriate for the response assessment of tall, highly irregular or critical infrastructure, this approach is not ideal for the development of analytical data for the construction of fragility functions for large building inventories. The reviewed studies have either adopted a simplified structural model and/or a simplified tsunami response analysis method in order to generate fragility functions with reduced computational time. However, it is difficult to assess the appropriateness of these simplifications from the published literature. It is also noted that none of the studies have taken the step of simplifying the earthquake response analysis through use of a pushoverbased approach, despite this being a common approximation made in the development of seismic fragility functions (e.g. [22], [23] and [24]).

This paper therefore presents a comprehensive comparison of different dynamic and static approaches for assessing the structural performance of buildings under sequential earthquakes and tsunami. It presents for the first time the sequential non-linear response history analysis of a building under these sequential hazards (with an intermediate free-vibration phase), and used this as a reference-case against which to assess the effect of analysis method simplification and of analysis implementation assumptions on the predicted structural response. To do this, a case study structure of a seismically and tsunami-designed Japanese vertical evacuation building is adopted. This same case-study building was first used in [12]. The case-study structure is assessed under systematically simplified representations of the earthquake, unloading and tsunami loading phases, and the structure response is compared to that obtained for the more realistic fully dynamic case. By so doing, the paper also aims to propose and assess the feasibility of adopting a simple double pushover approach for use in the assessment of low- to mid- rise regular buildings under sequential earthquake and tsunami loads.

In the following sections details of the different analysis methods and their combinations are first presented. The case-study building and loading specifics are then described. The response of the case-study building under sequential earthquake and tsunami hazards resulting from use of the different combinations of analysis approaches is presented. Insights are provided on the role of preceding earthquake damage on the tsunami response of the case-study building. Finally, recommendations are made on the combination of analysis approaches most suitable to different building assessment applications.

\section{METHODOLOGY}

The behaviour of a structure under earthquake and tsunami loading in sequence is assessed through three phases of analysis: the earthquake loading phase, an unloading phase where the structure comes to rest, followed by the tsunami loading phase. Analysis methods of different complexity can be adopted in each of these three phases. Table 1 lists the combinations of the analysis methods considered in order of decreasing complexity, with each of these further described in the following sub-sections. To help visualise the approaches discussed, an illustration of the three phases of the static nonlinear earthquake (PO), force-controlled unloading and tsunami pushover (TPO) analysis combination (PO-FC-CDPO and PO-FC-VDPO) is provided in Figure 1. 
Table 1. Different approaches to assess structural response under earthquake and tsunami in sequence.

\begin{tabular}{|c|c|c|c|c|}
\hline Complexity & Earthquake (EQ) & Unloading (UNL) & Tsunami (TS) & Abbreviation \\
\hline \multirow{7}{*}{ 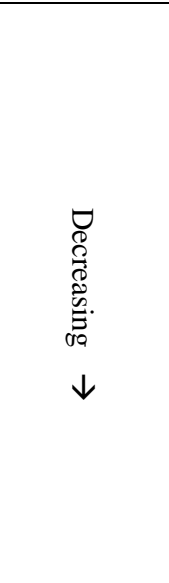 } & $\begin{array}{c}\text { Nonlinear Response } \\
\text { History Analysis } \\
\text { (DY) } \\
\end{array}$ & $\begin{array}{l}\text { Transient Free } \\
\text { Vibration (FV) }\end{array}$ & $\begin{array}{c}\text { Nonlinear Response History } \\
\text { Analysis } \\
\text { (TDY) } \\
\end{array}$ & DY-FV-TDY \\
\hline & \multirow{2}{*}{ DY } & \multirow{2}{*}{$\mathrm{FV}$} & $\begin{array}{c}\text { Static Constant Depth } \\
\text { Pushover (CDPO) }\end{array}$ & DY-FV-CDPO \\
\hline & & & $\begin{array}{l}\text { Static Variable Depth } \\
\text { Pushover (VDPO) }\end{array}$ & DY-FV-VDPO \\
\hline & \multirow{2}{*}{$\begin{array}{l}\text { Static Nonlinear } \\
\text { Pushover Analysis } \\
\text { (PO) }\end{array}$} & \multirow{2}{*}{$\mathrm{FV}$} & $\mathrm{CDPO}$ & PO-FV-CDPO \\
\hline & & & VDPO & PO-FV-VDPO \\
\hline & \multirow{2}{*}{$\mathrm{PO}$} & \multirow{2}{*}{$\begin{array}{l}\text { Static Force } \\
\text { Controlled } \\
\text { (FC) }\end{array}$} & $\mathrm{CDPO}$ & PO-FC-CDPO \\
\hline & & & VDPO & PO-FC-VDPO \\
\hline
\end{tabular}

In this paper, the structural response obtained using the most complex combination of the analysis methods, i.e. earthquake nonlinear response history analysis, followed by transient free vibration and tsunami response history analysis (DY-FV-TDY), is used as the reference-case against which to systematically measure the effect of adopting simplifying assumptions in the three phases of analysis. This analysis combination is also referred to as the "fully dynamic" case in the following text. Each combination of analyses is then applied to the assessment of the case study building presented in Section 3. 

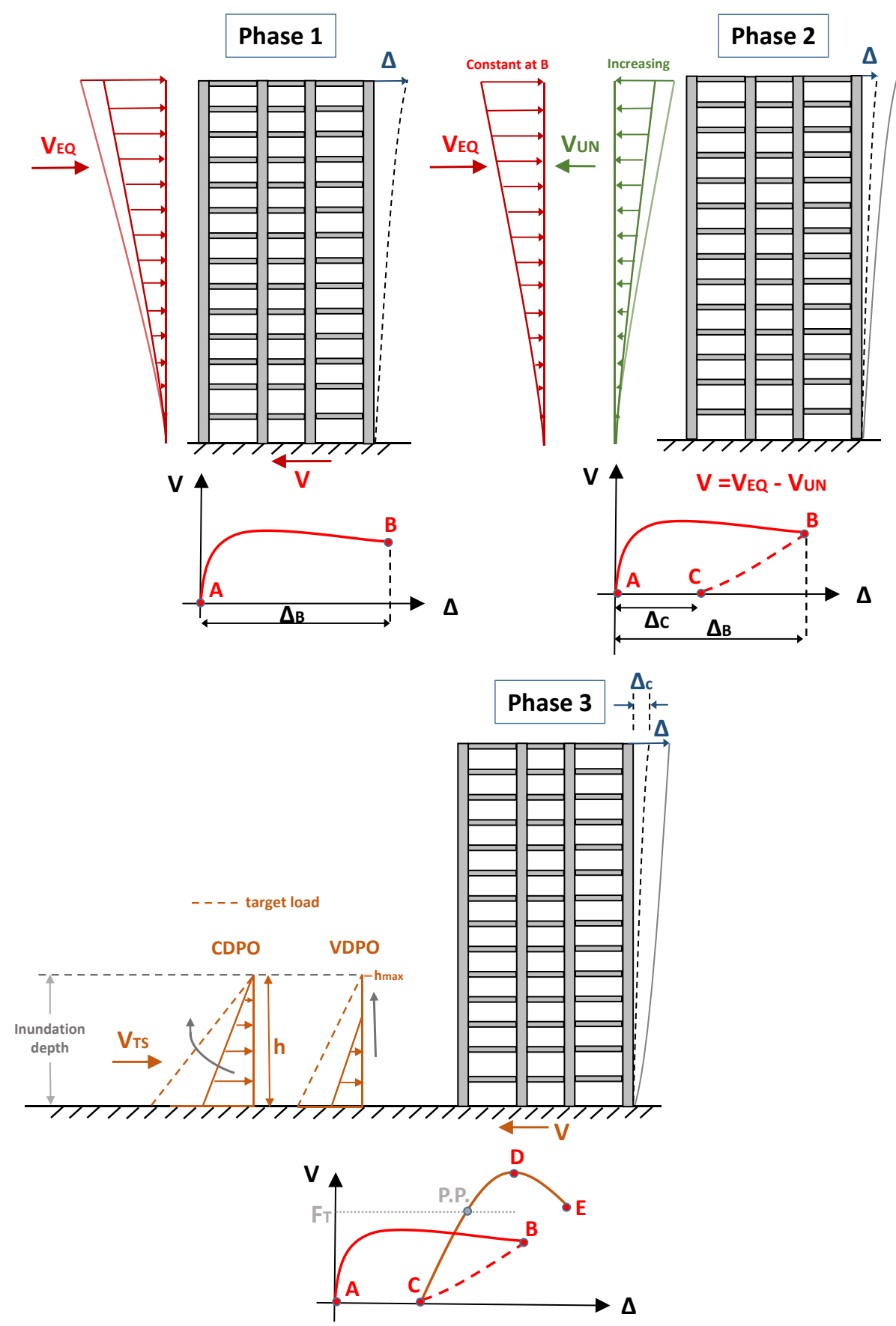

Figure 1. Illustration of the three phases of the static nonlinear earthquake, force-controlled unloading and tsunami pushover (TPO) analysis combination (PO-FC-CDPO \& PO-FC-VDPO): In phase (1) the earthquake pushover is conducted to point B on the pushover curve. In phase (2) the structure is unloaded through a force-controlled approach (i.e. branch B-C of the pushover curve). In phase (3) the structure is reloaded using a tsunami pushover approach: CDPO (branch C-E) or VDPO (branch C-D), and the structural performance is determined from the pushover curve at the applied tsunami force, $\mathrm{F}_{\mathrm{T}}$, i.e. at the performance point P.P.

\subsection{Representation of the earthquake loading and unloading phases}

The earthquake loading phase is represented either by a nonlinear response history analysis (DY) or by static nonlinear pushover (PO) with lateral load distribution corresponding to the first mode response of the structure (e.g. [25]). In both the PO and DY a number of engineering demand parameters (EDP) can be assessed throughout the analysis. These include, amongst others, the maximum inter-storey drift at each storey (IDR), roof displacement, base shear, floor accelerations and internal shear forces on structural elements.

In the unloading phase two approaches are used. The first approach is a transient free vibration analysis (FV), carried out over a time lapse sufficient to ensure that the structure is fully at rest at the end of this phase. FV can be applied both following the earthquake DY and PO analyses. The second and simpler, static force-controlled 
approach (FC) unloading is, instead, only applicable following an earthquake pushover analysis. In the FC approach, the same earthquake pushover lateral load pattern at the end of the previous phase is maintained, and an increasing reverse lateral load pattern of mirrored shape is applied until a zero nett base shear is achieved (see Figure 1).

If in the earthquake loading phase the structure has been deformed into the nonlinear range, a residual roof displacement (represented as $\Delta_{C}$ in Figure 1) is expected to be present. This residual displacement represents the damaged condition of the structure after the earthquake and prior to the tsunami arrival. It is noted that the residual displacement after unloading that is obtained for PO is always greater than that obtained after an "equivalent" DY analysis. This is a direct and well-known consequence of the choice of the PO analysis method (e.g. [26], [27]), and the discrepancy in residual roof displacement increases with increasing earthquake-induced structure nonlinearity. The size of the residual roof drift has particular implications here on predicted structural response under the subsequent tsunami, as discussed further in Section 5.0.

\subsection{Representation of the tsunami loading phase}

The tsunami loading phase is represented by three different analyses: tsunami nonlinear response history analysis (TDY), constant depth pushover (CDPO) and variable depth pushover analysis (VDPO). The CDPO and VDPO approaches are described briefly in Section 1, and more fully in [12]. In both pushover approaches, the structural performance is determined at the point of intersection between the tsunami pushover curve and a horizontal line representing the external tsunami force demand $F_{T}$, (such point is denoted as the performance point, P.P., in Figure 1). It is only at this performance point that there is consistency between the assumed lateral force distribution and the actual base shear [12]. It is highlighted that although Figure 1 illustrates the applied tsunami loading (Phase 3) as being applied through a triangular lateral load distribution, in this paper all the tsunami analyses are repeated for both triangular and trapezoidal lateral load distributions.

If the tsunami demand is larger than the residual structural capacity (i.e. $F_{T}$ is greater than the global strength associated to point D in Figure 1), then the structure is assumed to collapse. This definition of collapse implicitly assumes that the ductility does not play a significant role in the tsunami behaviour of the structure. The latter has recently been proven, albeit with significant assumptions by [16].

\section{APPLICATION CASE STUDY}

\subsection{Case-study building and numerical model}

The building used in this study corresponds to a 10-storey RC frame building, representative of a tsunami vertical evacuation building in Japan, designed for earthquake and tsunami effects. This case study structure was previously used by [12] to conduct a comparison of tsunami nonlinear analysis methods (TDY, CDPO and VDPO). The reader is referred to the latter article for a detailed description of the geometrical, material and detailing characteristics of the building. In this paper, the structure is modelled as a 2D moment resisting frame (representing a tributary width of $6 \mathrm{~m}$ ), with typical inter-storey heights of $3.9 \mathrm{~m}$ and a ground storey height of $4.5 \mathrm{~m}$ (total building height of $39.6 \mathrm{~m}$ ). The frame is composed of three bays, with total width of $23 \mathrm{~m}$ (see Figure $2 \mathrm{a}$ ). A numerical model of the structure is developed in OpenSees [28] considering a distributed plasticity approach to model the beam and column elements. The nonlinearBeamColumn element is used, considering five integration points along each element and the Gauss-Lobatto quadrature rule. In particular, for the column cross sections, the confinement of concrete is considered for the core concrete, with a $5 \mathrm{~cm}$ concrete cover being unconfined. The OpenSees materials Concrete04 and SteelO2 are adopted to represent the concrete and steel materials, respectively, with the former allowing for material stiffness degradation. Material strengths for concrete vary across the building height: Fc40 class (characteristic, $5^{\text {th }}$ percentile, strength $40 \mathrm{~N} / \mathrm{mm}^{2}$ ) for storeys 1-3, Fc36 for storeys 4-5, Fc30 for storeys 6 and 7 and Fc27 for the upper three storeys. Steel materials are SD390, (characteristic, $5^{\text {th }}$ percentile, strength of $390 \mathrm{~N} / \mathrm{mm}^{2}$ ), for longitudinal reinforcement and SD295 for transverse reinforcement. The columns are assumed fixed at their base and concentrated masses are considered at the mid-span of the interior beams (Figure 2a), assuming a mass per unit area equal to $1.2 \mathrm{t} / \mathrm{m}^{2}$.

The case study building has a sufficient height for it to be able to resist significant tsunami loads, and hence is chosen for its potential to assess the combined earthquake and tsunami effects on buildings. Its modal response shows a fundamental lateral structural period of $0.73 \mathrm{~s}$ and modal mass participation ratios of $77.9 \%, 12.2 \%$ and $4.5 \%$ for the first three modes of vibration. Considering the earthquake analysis of the case-study structure, it is acknowledged that response of this structure would not generally be classified as first-mode dominated, and therefore it would not traditionally be a candidate structure for response assessment using a pushover approach under earthquake alone. Despite this, Figure $2 b$ shows a reasonable correspondence between the global dynamic 
response of the structure under earthquake nonlinear response analysis (DY) and PO.

Figure $2 b$ shows the earthquake-only and tsunami-only pushover curves (TPO) for the structure. In particular, it shows the earthquake PO curve, CDPO curves for three inundation heights and VDPO curve for a maximum inundation depth $\left(h_{\max }\right)$ of $21 \mathrm{~m}$ and Froude number $\left(F_{r}\right)$ of 0.6 , (as assumed in [12]). A comparison of these curves clearly indicates that the structural behaviour under these two different types of loading is substantially different. For tsunami, the structure achieves greater strength and lower peak-displacements when compared to the earthquake case. In the case of CDPO, higher inundation depths yield smaller maximum strengths. This may be due to the increase of the lever arm and the bending moments at the ground storey as the inundation depth increases, and/or by the structure showing a reduced stiffness under higher inundation depths. While VDPO can only predict the structural behaviour up to the peak strength, CDPO can determine the degrading branch after peak strength. Comparison between the CDPO and PO responses also show a significantly reduced ductility of the structure under the tsunami loading. These observations are consistent for both triangular and trapezoidal lateral load distribution assumptions for the tsunami analysis. The procedure for assessing the outputs of CDPO and VDPO analyses, when compared to TDY, is given in [12] and is replicated later in this document.

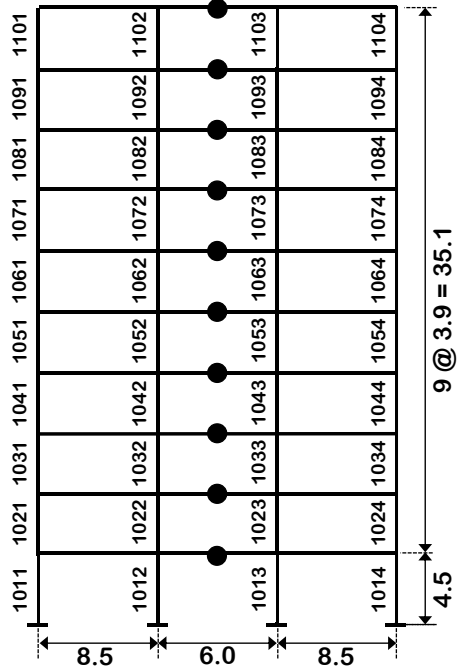

a)

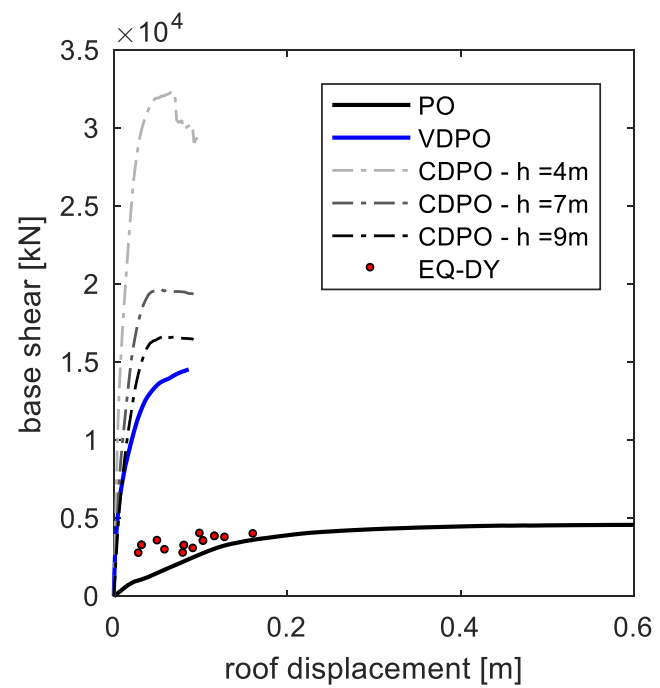

b)

Figure 2. (a) Schematic view of the assessed RC frame model. (b) Earthquake-only and tsunami-only pushover curves of the assessed RC structure. All tsunami analyses shown assume a triangular lateral load distribution. The red dots labelled as 'EQ-

DY' correspond to the maximum base-shear and maximum roof displacement results from the earthquake DY analyses.

\subsection{Earthquake and tsunami time-histories}

To carry out the nonlinear dynamic analyses (DY and TDY), a set of compatible earthquake-tsunami records is considered (Figure 3), based on the work of [4]. In [4] ground-motion time histories are simulated for the 2011 Tohoku Japan earthquake, using a multiple-event stochastic finite-fault method. The resulting tsunami inundation time histories are obtained through multiple realizations of wave profiles in which the nonlinear shallow water equations with run-up are evaluated. From the available 672 earthquake-tsunami pairs, 16 specific pairs are selected here, aiming to cover a wide range of spectral acceleration, $\mathrm{Sa}(\mathrm{T}=0.73 \mathrm{~s})$, and tsunami peak force, $\mathrm{F}_{\mathrm{T}}$, values. Table 2 in the Appendix presents the detailed characteristics of the 16 earthquake-tsunami (E-T) pairs used in this study.

The tsunami force time history is calculated from the selected tsunami inundation depth, $h(t)$, and velocity, $u(t)$, time histories using the formulation in [10], for estimating forces on partially immersed rectangular bodies in quasi-steady flows. The use of this formula assumes that a steady-state flow is representative of the tsunami inundation, which assumption has been shown to be reasonable by [11]. According to [10], the tsunami force $F_{T}$ $(t)$ per unit of width $(b)$ can be estimated as:

$$
\frac{F_{T}(t)}{b}=\operatorname{sgn}(u)\left\{\begin{array}{cl}
0.5 C_{D} \rho u^{2} h & \text { if } F_{r}<F_{r c} \\
\lambda \rho g^{\frac{1}{3}} u^{\frac{4}{3}} h^{\frac{4}{3}} & \text { if } F_{r} \geq F_{r c}
\end{array}\right.
$$

where $C_{D}$ is the drag coefficient, $\rho$ is the sea water density $\left(1,200 \mathrm{~kg} / \mathrm{m}^{3}\right), \operatorname{sgn}(u)$ is the sign function of the flow velocity, $g$ is the acceleration of gravity, $\lambda$ is the choking ratio. $F_{r}=u / \sqrt{g} \cdot h$ is the Froude number of the flow and $F_{r c}$ is the Froude number threshold, which denotes subcritical $\left(F_{r}<F_{r c}\right)$ and choked $\left(F_{r} \geq F_{r c}\right)$ conditions for the steady- 
state flow. The reader is referred to the mentioned studies for more detail on the determination of $F_{r c}, C_{D}$ and $\lambda$, which are dependent on the blocking ratio parameter $b / w$. The latter parameter is indicative of the amount of blocking imposed by the structure on the flow, and can be assumed representative of urban building density. A blocking ratio of 0.6 is assumed in this paper, with corresponding values of $C_{D}=4.7, \lambda=2.0$ and $F_{r c}=0.32$. These are the same values assumed in [12] on the basis of [10].

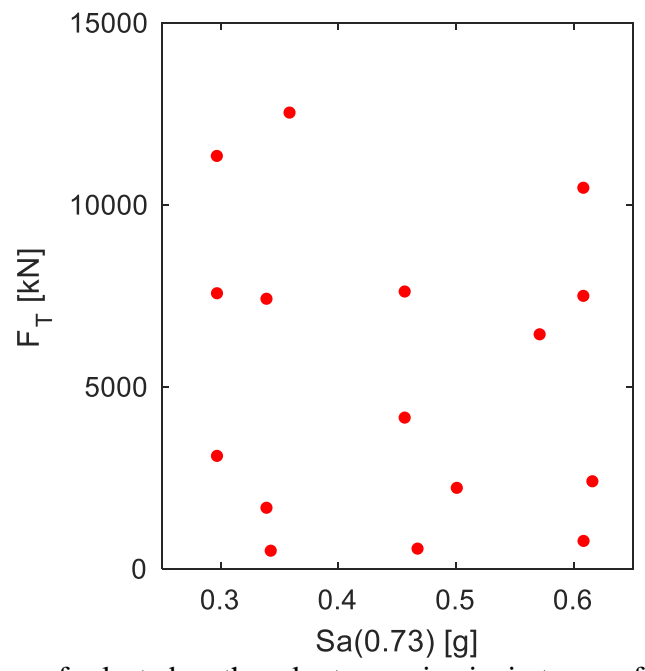

Figure 3. Summary of selected earthquake-tsunami pairs in terms of $\mathrm{Sa}(\mathrm{T}=0.73 \mathrm{~s})$ and $\mathrm{F}_{\mathrm{T}}$.

\subsection{Application of the earthquake loading and unloading phases}

Each earthquake pushover (PO) analysis is carried out until reaching the target IDR value at the same storey of the corresponding DY analysis, as explained in Section 2. The lateral load pattern follows the shape of the fundamental mode of the structure. Displacement increments of 2/10,000 times the building height are considered, and the roof displacement is controlled using a displacement-control solver. In the case of the nonlinear response history analyses (DY), a Newmark integrator with $\gamma=0.5$ and $\beta=0.25$ is used, and an internal damping ratio of $\zeta=5 \%$ is considered. This Raleigh damping value, though a little high, is within the common range of values used for finite element models of mid-rise reinforced concrete moment resisting frames [29] and provides stability to the analyses. Moreover, variation in the Raleigh damping is seen not to greatly influence the combined earthquake and tsunami sequential response, due to the quasi-static nature of the latter [16]. The integration time step is reduced in case of convergence issues.

The quasi-static unloading procedure, FC, considers 500 incremental steps in applying the mirrored lateral load pattern to the point of zero net applied lateral force. A load control solver is used for this procedure. Conversely, the dynamic free-vibration unloading procedure, FV, is carried out over a duration of 10 s following the earthquake loading phase, assuming a fictitiously high damping ratio of $\zeta=30.0 \%$ and using a Newmark integrator with the same $\gamma$ and $\beta$ values as in the previous stage.

As mentioned in Section 2.1, to assess the feasibility of using PO instead of DY for characterising the earthquake loading phase in a sequential earthquake and tsunami building assessment, great care has to be taken in determining the "equivalence" condition for comparing the two approaches. If a predictive assessment of a building's performance under earthquake and tsunami sequential loading, if PO were to be used for the earthquake loading phase, then a capacity spectrum approach such as [23] could be used to define the point at which to stop the earthquake pushover analysis (i.e. point B in Figure 1). However, all capacity spectrum approaches adopt some form of idealisation of the earthquake pushover curve in their application (e.g. simplify them to bi-linear or trilinear curves e.g. [24]). Amongst other factors, this idealisation introduces errors in their ability to predict the earthquake response of buildings with respect to earthquake non-linear response history analyses.

Hence, in this paper a direct comparison of EDPs resulting from PO and DY are instead adopted to define when a PO is stopped (i.e. point B in Figure 1) such that it can be considered "equivalent" to the DY conducted for a particular ground motion. The best equivalence criterion is assumed to be that which recreates the same damage state and damage distribution in the structure under the DY and PO earthquake analysis methods. As inter-storey drift ratio $(I D R)$ is widely used in earthquake fragility studies to indicate structural damage [22], here the PO analysis is stopped when the case-study building experiences an IDR equal to the maximum inter-storey drift ratio value observed in the DY $\left(I D R_{\max , D Y}\right)$, at the same storey at which it was observed in the DY analysis. Comparison 
of IDR profiles over the structure height obtained with DY and PO, shows that in some PO analyses when this "equivalence" criterion is reached $I D R$ values greater than the $I D R_{\max , D Y}$ can be achieved in the upper storeys of the building. However, as these storeys do not play a critical role in resisting the subsequent tsunami loading, the adopted criterion is deemed appropriate for determining PO and DY equivalence, and is used throughout the paper.

\subsection{Application of the tsunami loading phase}

Starting from the rest condition after the earthquake excitation (e.g. point $\mathrm{C}$ in Figure 1), the analyses characterising the tsunami loading phase (TDY, VDPO and CDPO) are performed. In each case a discretisation of 5 discrete loads per storey applied at the left-hand side of the structure (e.g. column 1011 and upwards in Figure 2a). This discretisation is used based on the results of, which shows that this assumption provides a good balance between accuracy and computational effort. The dynamic parameters to analyse the structure under TDY are the same as in the earthquake case, with a reduction of the time step used in case of convergence issues.

For the CDPO analyses, a displacement control integrator is used, similarly to the earthquake pushover case. When CDPO is compared to TDY for the selected tsunami inundation time histories, the CDPO is evaluated at an inundation depth, $h^{\text {peak }}$, which corresponds to that achieved in the inundation time history at the time of occurrence of its peak applied tsunami force $\left(F_{T}\right)$. This criterion is adopted instead of the maximum inundation depth, which is typically used in past studies (e.g. [15]), for three reasons. Firstly, use of an $F_{T}$-consistent depth for the CDPO analysis means that the velocity, and hence the Froude number, of the flow is the same for the CDPO and TDY analyses at their point of comparison. This same Froude number value, $F_{r}{ }^{\text {peak }}$, is also used in the VDPO analysis. Secondly, applied tsunami force has been seen to be a better predictor of structural response under tsunami inundation than the maximum tsunami inundation depth [30]. For the VDPO analyses, the inundation depth is varied from $0 \mathrm{~m}$ up to a maximum value of $h^{\max }$ of $21 \mathrm{~m}$, in 300 increments. In this case, a force control integrator is considered. When VDPO is compared to TDY, the value of Froude number adopted for the VDPO, $F_{r}^{\text {peak }}$, is that achieved in the inundation time history at the time of occurrence of its peak applied tsunami force $\left(F_{T}\right)$.

The TDY, CDPO and VDPO analyses are repeated twice: assuming triangular and trapezoidal tsunami applied lateral load distributions.

\section{COMPARISON OF APPROACHES}

This section presents a comparison of the structural responses obtained when the combinations of earthquake loading, unloading, and tsunami loading analysis methods presented in Table 1 are applied to the case study structure. In this comparison, the response evaluation considers the global behaviour in terms of base shear versus roof displacement, storey-level behaviour in terms of inter-storey drift (IDR), and local response through the evaluation of the internal shear force over Column 1011. Column 1011 is chosen as it is the most critical column under tsunami loading conditions.

The results are presented as follows:

1. Presentation of the reference case for further comparisons: DY-FV-TDY.

2. Comparison between the reference case and DY-FV-CDPO and DY-FV-VDPO, to determine how analysis simplifications and assumptions on lateral load distribution in the tsunami loading phase affect the overall response under cascading earthquake and tsunami hazard.

3. Comparison of the results presented in 1 and 2, with the PO-FV-CDPO/VDPO analysis combinations to determine how analysis simplification in the earthquake loading phase, along with the assumptions presented in Section 2.1, affect the overall response under cascading earthquake and tsunami hazard.

4. Comparison between the results presented in 1 and 3, with the PO-FC-CDPO and PO-FC-VDPO analysis combinations to determine the effect of the simplified static unloading procedure (FC) on the overall response under cascading earthquake and tsunami hazard.

\subsection{The fully dynamic case (DY-FV-TDY)}

The combination of earthquake response history analysis, free vibration unloading and tsunami response history analysis (DY-FV-TDY), the "fully dynamic" case, is adopted in this paper as the reference case against which to compare all other analysis method combinations. The DY and TDY analyses are carried out on the case-study building for all the 16 coherent pairs of earthquake and tsunami loading histories (E-T) presented in Section 3.2. As an example, the resulting base shear - roof displacement response histories and IDR envelopes at the point of maximum displacement after the tsunami loading phase are shown in Figure 4 for the earthquake-tsunami pairs $E$ $T-21$ and $E-T-11$. These E-T pairs have been selected as representative of similar levels of earthquake excitation but different levels of tsunami intensity, (i.e. for $E-T-21, \mathrm{Sa}(0.73 \mathrm{~s})=0.572 \mathrm{~g}, F_{T}=6,411 \mathrm{kN}$; whilst $E-T-11$ has 
$\mathrm{Sa}(0.73 \mathrm{~s})=0.617 \mathrm{~g}$ and $\left.F_{T}=2,373 \mathrm{kN}\right)$. For clarity, Figure 4 only shows the final tsunami response histories, with the preceding earthquake effect being evident from the tsunami loading starting from a residual deformation. Figure 4 shows the results of the fully dynamic analyses obtained using both triangular (DY-FV-TDY TRIANG) and

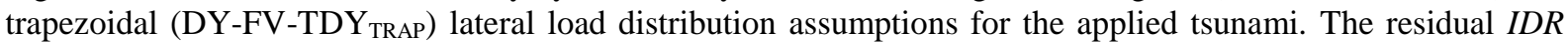
profiles after the DY-FV completion have also been included.

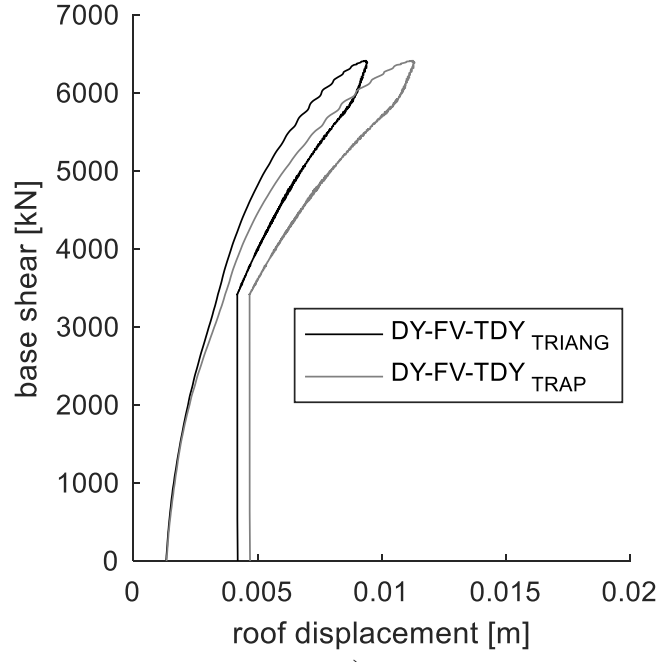

a)

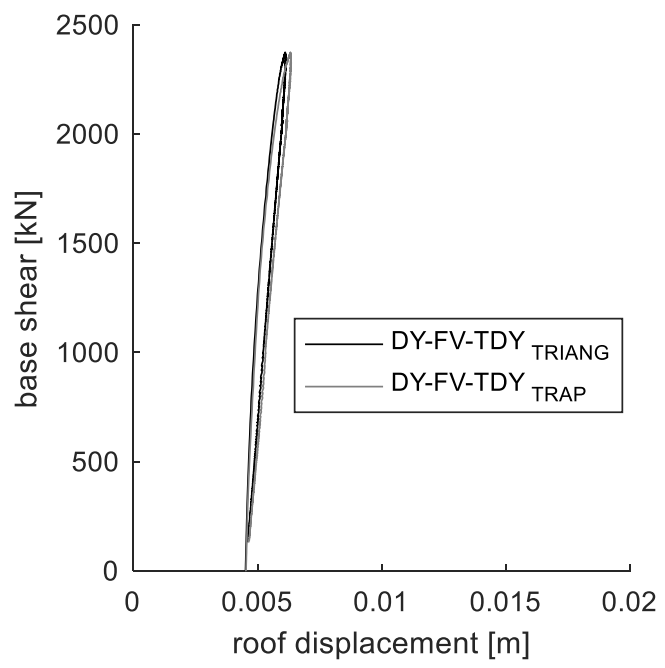

c)

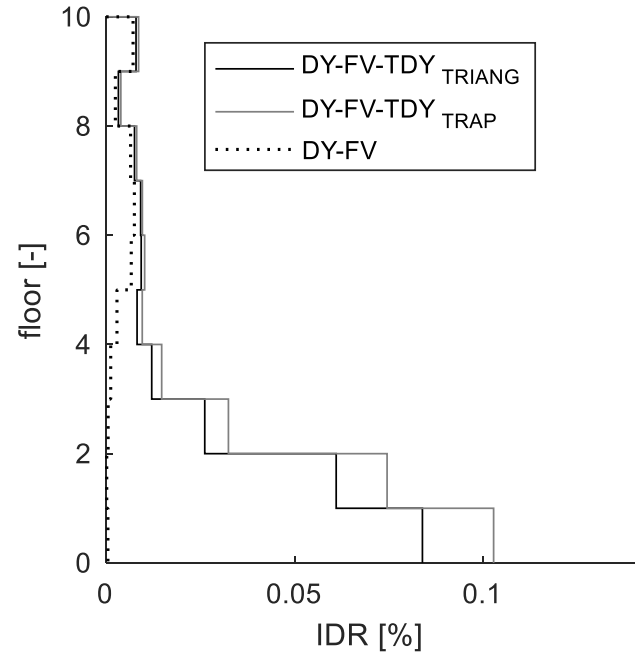

b)

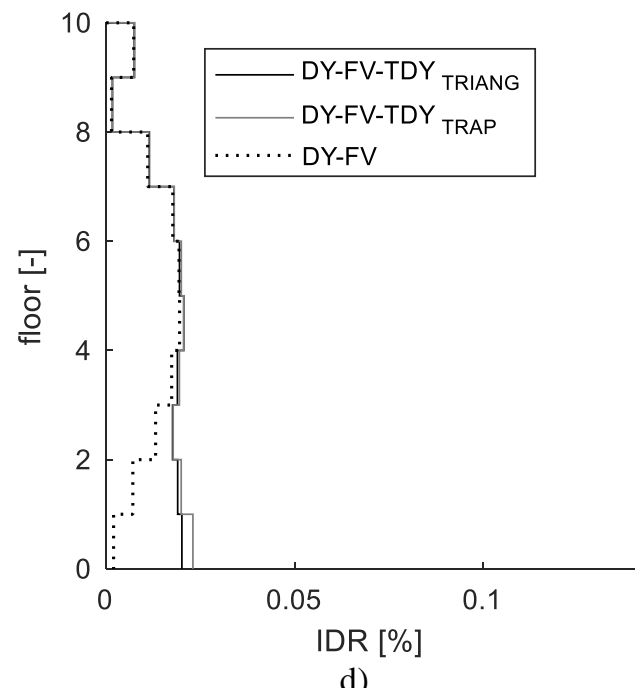

d)

Figure 4. Response history for two different earthquake-tsunami records (top: $E-T$-21, bottom: $E-T-11$ ):

(a) and (c) show the tsunami base shear- roof displacement envelopes; (b) and (d) show the tsunami inter-storey drift ratio response at the point of maximum roof displacement for DY-FV-TDY and the residual IDR in the structure after DY-FV. Results are plotted for both triangular and trapezoidal tsunami lateral load distribution assumptions.

For both E-T pairs the earthquake is seen to induce higher residual inter-storey drifts at mid-height of the casestudy building (Figure $4 \mathrm{~b}$ and $4 \mathrm{~d}$ ). However, when the tsunami loading is applied, the IDR values are significantly increased at the lower stories of the structure and, as expected, in the case of the higher tsunami intensity, the tsunami response dominates, resulting in a concentration of structural deformation at the ground floor (e.g. Figure 4b). It is noted that in the case of some of the other earthquakes within the E-T suite, the maximum inter-storey drift from the earthquake occurs in the upper storeys. Again in those cases, it is observed that when the tsunami intensity is relatively large, the damage distribution shifts to the lower storeys after the earthquake and tsunami loading sequence. It is noted that in all the E-T analyses, residual deformations from the earthquake phase of loading coincided in direction with the direction of the applied tsunami loading. If this were not the case, the analysist might consider applying the tsunami loading in the same direction as the predominant residual deformation, for conservatism.

As illustrated in Figure 4, when the trapezoidal lateral load distribution is used to apply the tsunami loading, larger 
roof displacement and the $I D R$ values at lower storeys are predicted. This is true for all 16 E-T pairs, with the differences between 5-31\% in IDR at the ground storey; the larger discrepancies occurring for larger tsunami force. Much smaller differences of up to $3 \%$ are instead observed when the predicted shear internal force for column 1011 is compared for the two assumed lateral load distributions. These findings highlight a high sensitivity of building deformation prediction to tsunami lateral load distribution choice but an insensitivity of this choice on critical element shear. Consequently, as ground-storey column shear failure is the failure mechanism in the casestudy building, (as shown in [12]), the collapse prediction of the structure under sequential earthquake and tsunami loads is also insensitive to choice of applied tsunami lateral load distribution.

\subsection{The effect of using earthquake dynamic analysis with tsunami pushover (DY-FV-CDPO/VDPO)}

Figure 5 shows a comparison between the final structural response obtained in the fully dynamic case and those obtained when the tsunami loading phase analysis is characterised by either a CDPO or VDPO analysis. In the case of DY-FV-TDY, the structural response is assessed directly from the analysis, whereas for DY-FV-CDPO and DY-FV-VDPO, the final structural response is estimated at the point of intersection of the tsunami pushover curves with a base shear value equal to the peak tsunami force of the corresponding inundation time history (referred to as the performance point). The analysis is repeated for both triangular and trapezoidal assumptions for the applied tsunami lateral load distributions (though Figure 5 only shows the results for the triangular load distribution assumption).

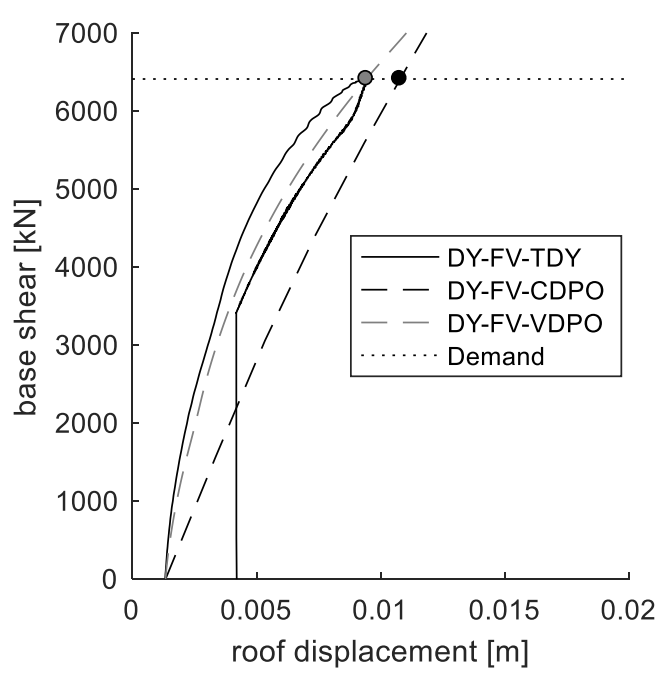

a)

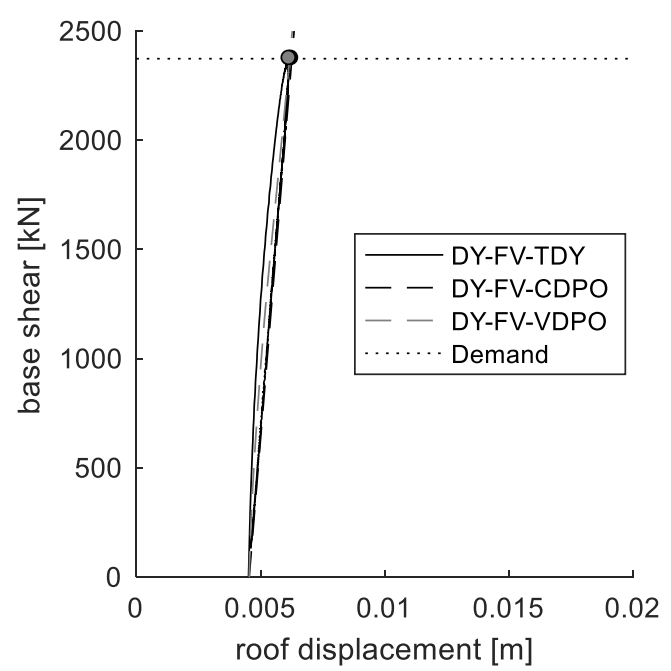

c)

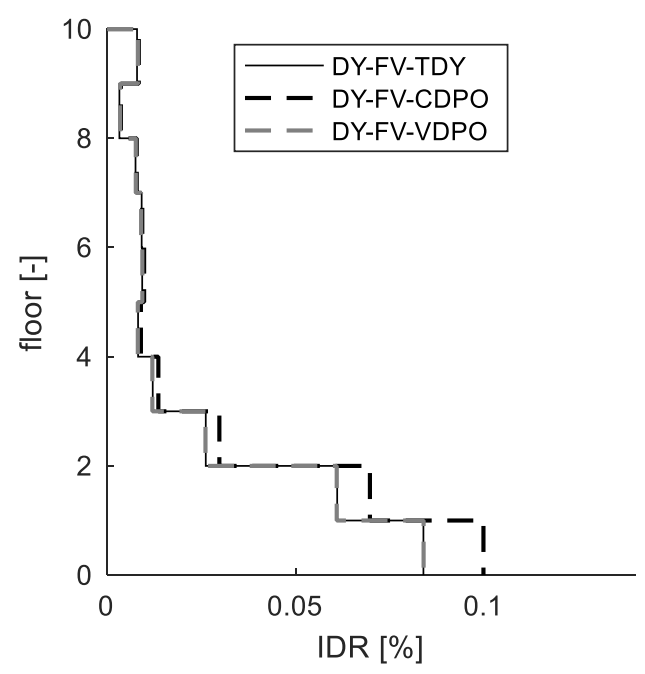

b)

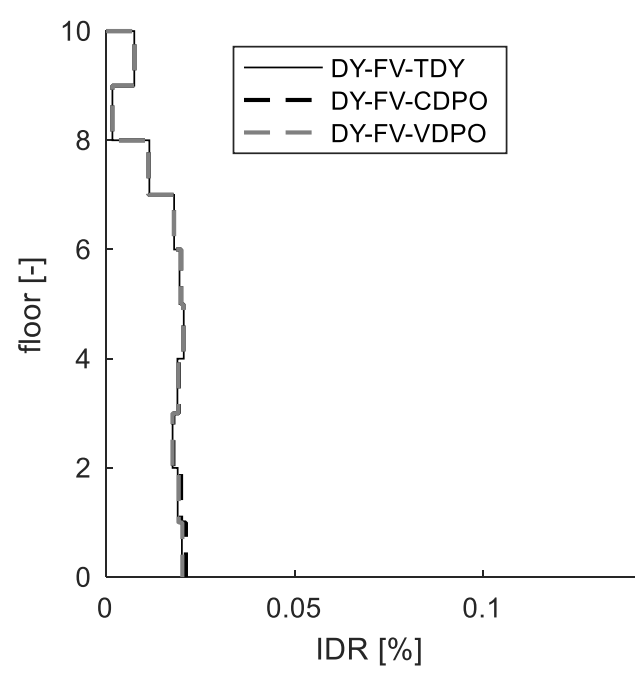

d)

Figure 5. Comparison of DY-FV-TDY, DY-FV-CDPO and DY-FV-VDPO results for two different earthquake-tsunami records (top: $E-T-21$, bottom: $E-T-11$ ): (a) and (c) show the base shear- roof displacement envelopes of the structure under the tsunami loading phase. In these figures the tsunami pushover performance points are highlighted with circles. (b) and (d) show the $I D R$ profile in height obtained under the sequential earthquake and tsunami loading. For the tsunami pushover cases, these IDR profiles have been determined at the performance points. For DY-FV-TDY the IDR profile has been read at the time of maximum roof displacement during the tsunami loading phase. The figure shows the results obtained using a triangular lateral load distribution for the applied tsunami loading phase. 
Figure 5a and $5 \mathrm{c}$ show that tsunami pushover methods predict reasonably well the global structural response when compared with the fully dynamic case. The DY-FV-VDPO also predicts well the final IDR distribution in the structure (Figure 5b and 5d). Instead, under the applied earthquake and tsunami sequence, the CDPO analyses result in a slight overestimation of $I D R$ when compared to VDPO. This is especially evident for the IDR values at the lower stories (i.e. the ones most affected by the tsunami loading). These observations are consistent for both the triangular and trapezoidal load distributions assumed, but with the trapezoidal load distribution inducing larger $I D R$ values at lower storeys than the triangular case, for both CDPO and VDPO. Choice of lateral load distribution for the applied tsunami force has no significant effect on the internal shear force prediction for column 1011. This is clearly seen in Figure 6, which illustrates the performance of DY-FV-CDPO and DY-FV-VDPO in predicting the ground storey IDR $\left(I D R_{l}\right)$ and the shear internal force in column 1011 as compared to the fully dynamic case, for the $16 \mathrm{E}-\mathrm{T}$ pairs, and two assumed tsunami lateral load distributions. Figure 6 shows that DY-FV-VDPO results in smaller errors in predicted $I D R_{I}$ (maximum 26\%) and in predicted shear internal force for column 1011 (maximum 3\%). Instead, DY-FV-CDPO is seen to overestimate $I D R_{l}$ by up to $50 \%$, whilst underestimating the shear internal force in column 1011 by up to $13 \%$. The latter underestimation in ground storey column shear is also observed in [15] for their tsunami only assessment.

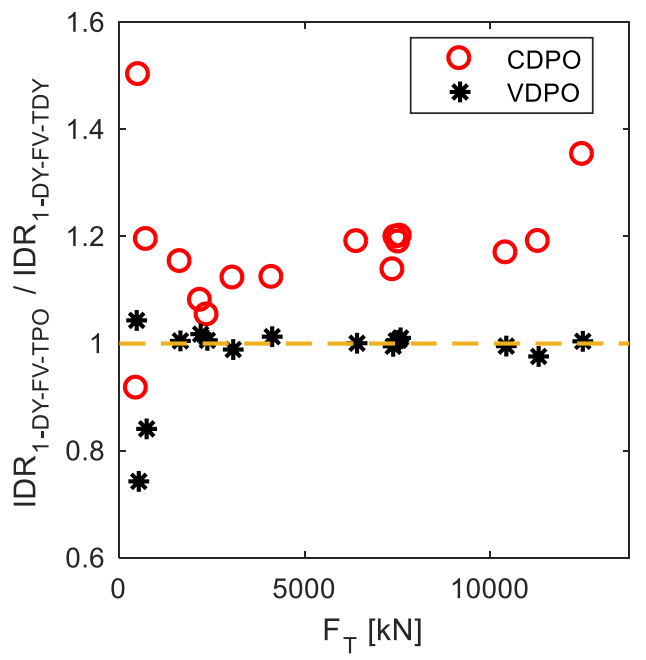

a)

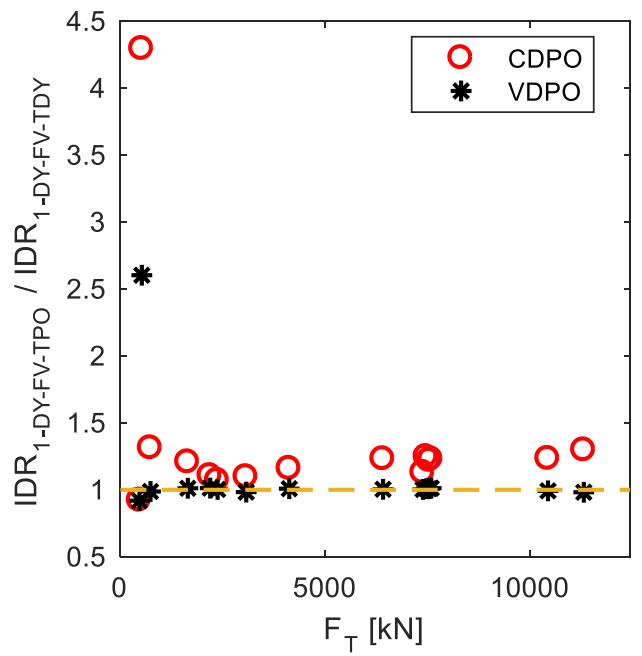

c)

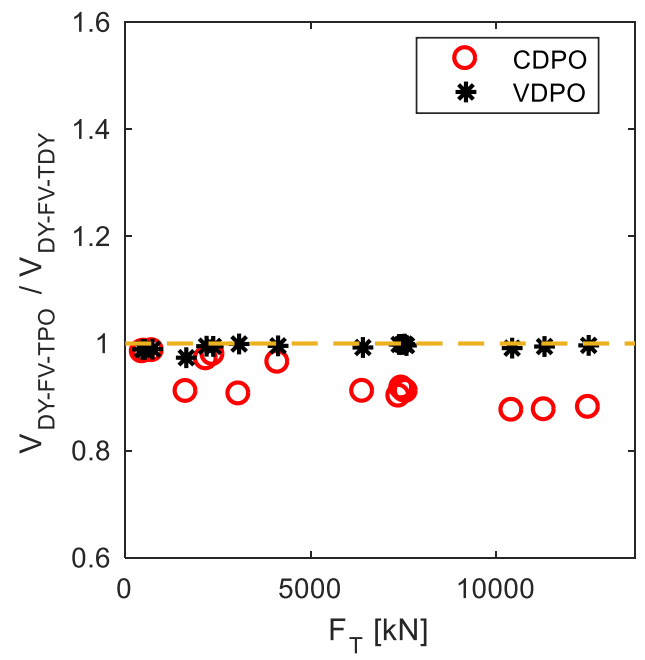

b)

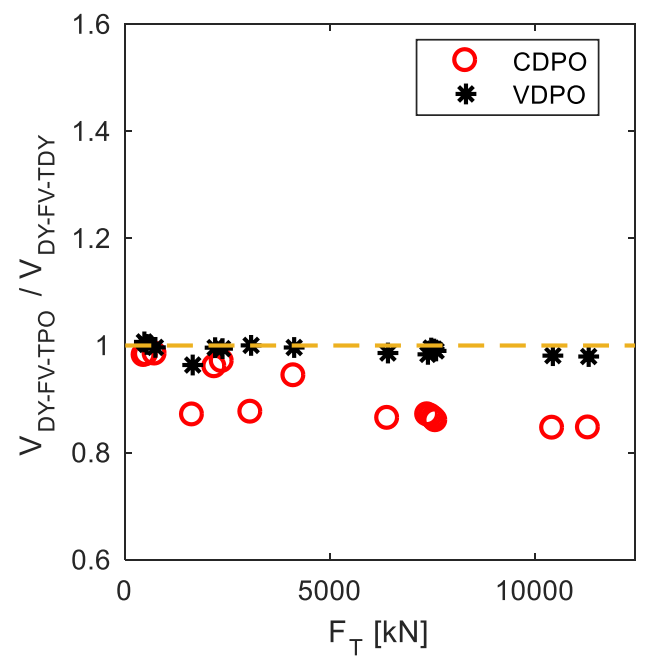

d)

Figure 6. Comparison of structural response parameters obtained under DY-FV-TDY and DY-FV-TPO, where TPO corresponds to the pushover methods CDPO and VDPO. (a) and (c) ratio of $I D R$ at ground storey versus $F_{T}$, for the triangular and trapezoidal tsunami lateral load distributions, respectively; (b) and (d) ratio of shear internal force for column 1011 versus $F_{T}$, for the triangular and trapezoidal tsunami lateral load distributions, respectively.

\subsection{The effect of using earthquake and tsunami pushover approaches (PO-FV-CDPO and PO-FV-VDPO):}




\section{The double pushover approach}

This section looks at the effect on the overall predicted structural response to earthquake and tsunami loading in sequence of using pushover approaches for both the earthquake and tsunami loading phases. Figure 7 presents the comparisons for the two earthquake-tsunami records previously presented (E-T-21 and $E-T-11)$. For clarity, Figure 7 only presents the results of the final tsunami loading phase for the triangular tsunami lateral load case. For $E-T$ 21 (Figure 7a-b), unloading from the earthquake pushover curve (from $I D R_{\max \_D Y}=0.367 \%$ ) results in a similar residual displacement to that observed in the DY case. This in turn results in similar global estimates of the structural response in the tsunami loading phase, with the PO-FV-TPO estimates being slightly larger than those obtained from DY-FV-TPO in terms of displacements and IDR values. This observation is common across all analyses where the earthquake loading phase induces small to moderate levels of nonlinearity (damage) in the structure, and suggests that the double pushover approach may be adequate in these cases.

In the case of $E-T-11$, which induces a much larger $I D R_{\text {max }} D Y(=0.670 \%)$ in the earthquake phase, a significant residual displacement remains after the earthquake pushover. Such a residual displacement is not observed in the earthquake response history analysis. This results in a shift along the displacement axis of the subsequent tsunami pushover curves with respect to the DY-FV-TPO cases. For the particular case of E-T-11, given the tsunami intensity is relatively low, the tsunami pushover does not significantly modify the IDR profile resulting from the earthquake pushover analysis. Hence, the final IDR profile in PO-FV-TPO is significantly different from the DYFV-TPO case. This same observation is seen for all $E-T$ cases where the earthquake significantly pushes the structure into the nonlinear range under the pushover analysis and the discrepancy is particularly severe if the subsequent tsunami is of small intensity (e.g. Figure 8a).

Despite the observed differences in $I D R$ profile resulting from use of earthquake pushover instead of response history analysis, as seen in Figure 8b, PO-FV-VDPO predicts reasonably well the internal shear force in the critical column (1011) of the case-study building when compared to the fully dynamic approach. This is explained as the shear internal force at the ground storey of the building is driven by the tsunami loading; observation which is sustained by the lack of difference in shear internal force values when the earthquake analysis type is changed, whilst a visible difference in shear internal force results when the tsunami analysis is changed from CDPO to VDPO (Figure 8b). Comparison of PO-FV-VDPO and PO-FV-CDPO shows that the former provides a better prediction than the latter, with PO-FV-CDPO underestimating the shear internal force by up to $14 \%$ for the cases with higher tsunami peak forces. These observations are consistent for both triangular and trapezoidal tsunami lateral load assumptions, again with choice of tsunami lateral load distribution having a significant effect on the predicted deformed shape (with trapezoidal predicting larger deformations) but no significant effect on the predicted critical column internal shear.

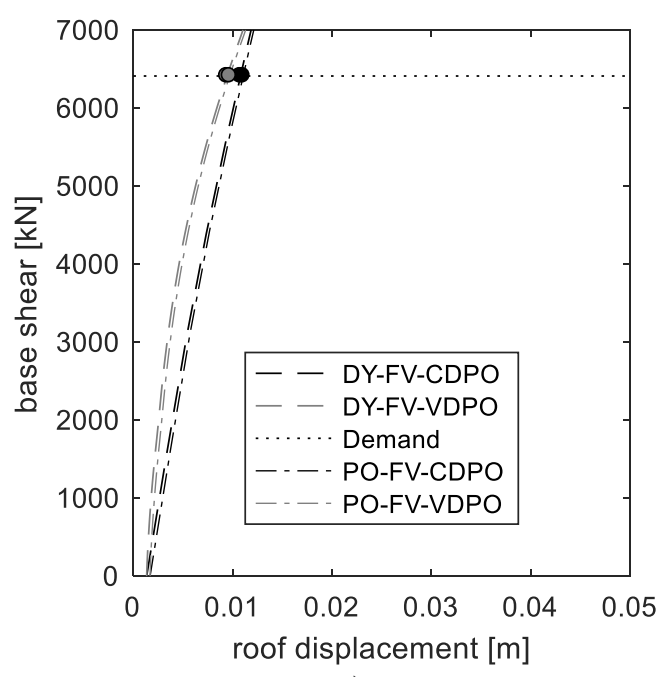

a)

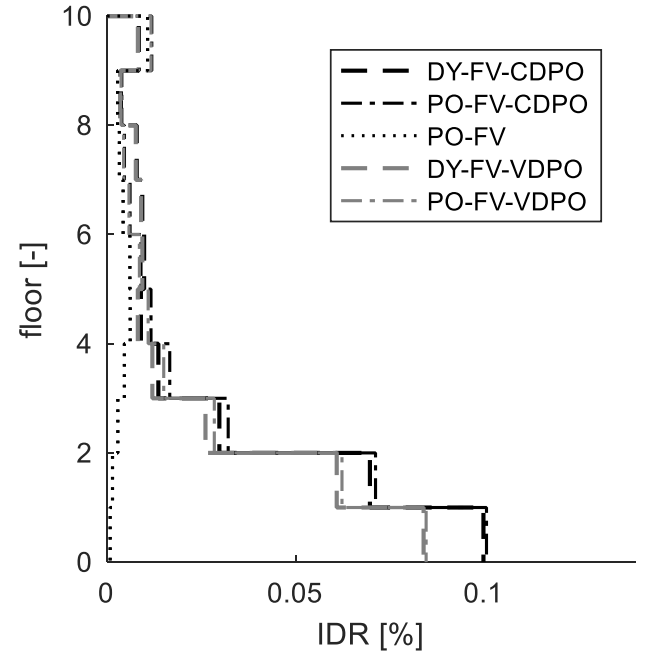

b) 


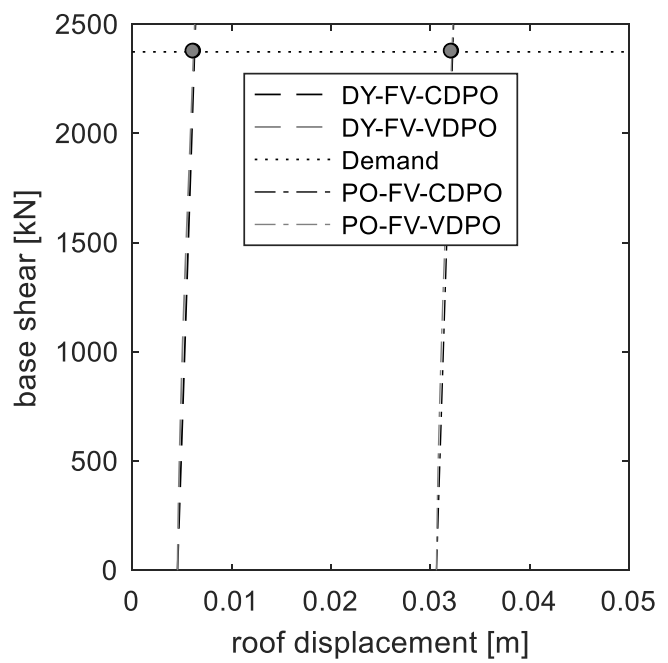

c)

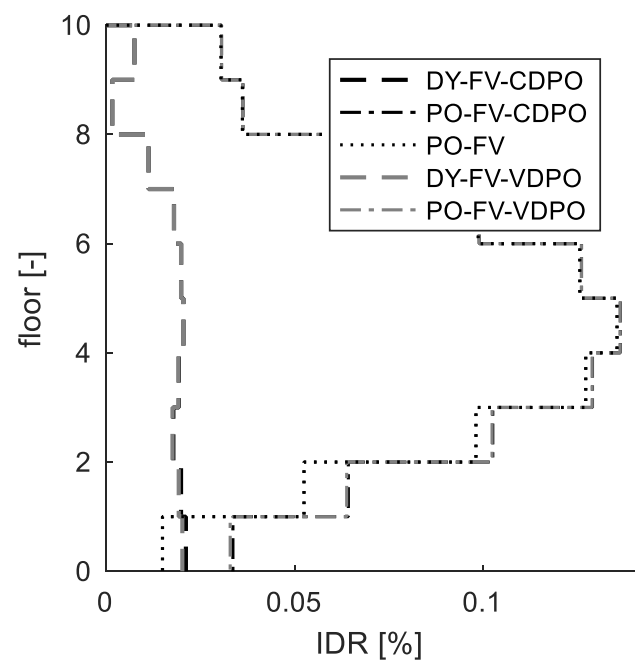

d)

Figure 7. Comparison of DY-FV-TPO versus PO-FV-TPO analyses for two cases (top: E-T-21, bottom: E-T-11): (a) and (c) show the tsunami base shear - roof displacement envelopes; (b) and (d) show the IDR profile across the structure height at the tsunami performance points. The figure shows the results obtained using a triangular lateral load distribution for the applied tsunami loading phase.

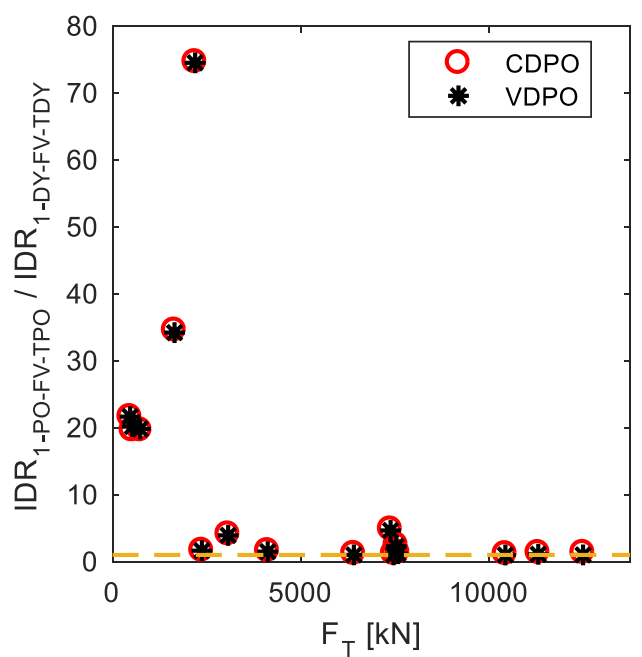

a)

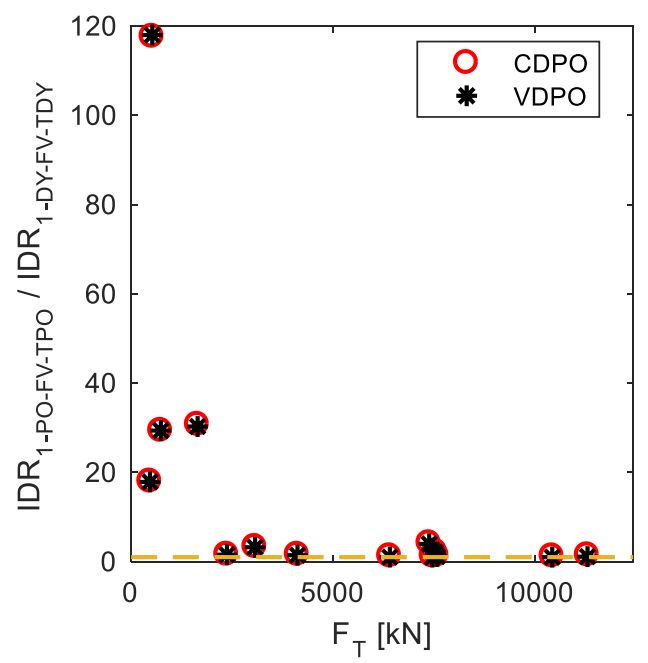

c)

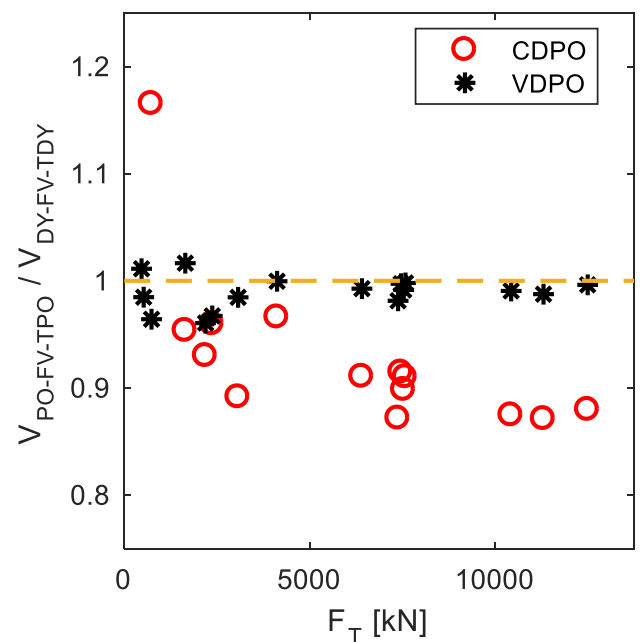

b)

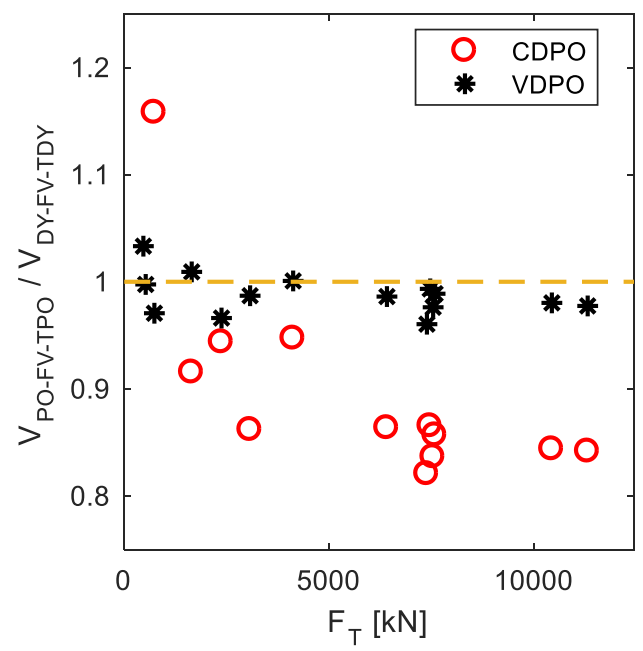

d)

Figure 8. Comparison of structural response parameters obtained under DY-FV-TDY and PO-FV-TPO, where TPO corresponds to the pushover methods CDPO and VDPO. (a) and (c) ratio of IDR at ground storey versus $F_{T}$, for the triangular 
and trapezoidal tsunami lateral load distributions, respectively; (b) and (d) ratio of shear internal force for column 1011versus $F_{T}$, for the triangular and trapezoidal tsunami lateral load distributions, respectively

\subsection{The effect of using Free Vibration or Force Controlled unloading on the double pushover analysis (PO- FV-TPO and PO-FC-TPO)}

This section presents an assessment of the effect on the overall predicted structural response due to choice of unloading procedure, when both the earthquake and the tsunami load phases are analysed with static pushover. Figure 9 presents a summary of the ratio of inter-storey drift at ground storey and shear internal force in the critical column obtained through the use of PO-FC-VDPO/CDPO versus those obtained from the fully dynamic case. When Figures 8 and 9 are compared, it is seen that use of the simpler Force-Controlled unloading (FC) in the double pushover, results in only a slightly poorer prediction of the IDR at the end of the tsunami phase than when Free Vibration (FV) is used. A more detailed look at the analyses shows that this derives directly from the fact that when FC is used, larger residual displacements in the structure are predicted following the unloading phase. In terms of the internal shear force in column 1011, the estimate given by PO-FC-VDPO/CDPO does not differ significantly from that obtained with PO-FV-VDPO/CDPO. The analysis PO-FC-VDPO again provides the better estimate of the internal shear force, whereas PO-FC-CDPO underestimates it by $14-15 \%$ in the case of moderate to high tsunami peak forces and overestimates it by up to $8 \%$ for low tsunami intensities. These observations are consistent for both triangular and trapezoidal applied tsunami lateral load distribution assumptions, so Figure 9 only illustrates the triangular case.

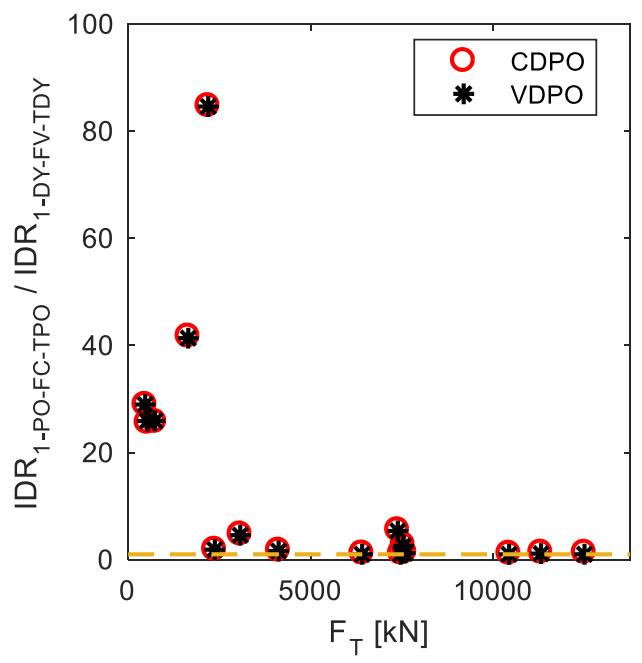

a)

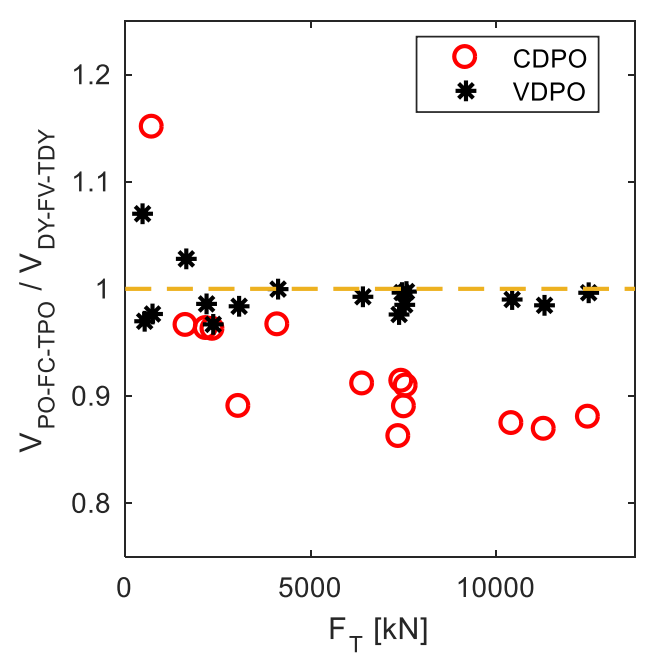

b)

Figure 9. Comparison of structural response parameters obtained under DY-FV-TDY and PO-FC-TPO, where TPO

corresponds to the pushover methods CDPO and VDPO. (a) ratio of IDR at ground storey versus $F_{T}$; (b) ratio of shear internal force for column 1011versus $F_{T}$. The figure shows the results obtained using a triangular lateral load distribution for the applied tsunami loading phase.

\subsection{Summary}

Section 4.2 shows that, when compared to the fully dynamic case, use of DY-FV-TPO can reproduce well the case study building response under the tsunami loading phase. In particular, use of DY-FV-VDPO provides a better prediction of roof displacement, maximum inter-storey drift and ground storey column internal shear than DYFV-CDPO. These results strongly suggest that DY-FV-VDPO can be used in the place of a fully dynamic analysis for assessing building response under sequential earthquake and tsunami loads.

Section 4.3 shows that analysing the building response using a double-pushover approach can result in a significant discrepancy in the IDR profile predicted after the tsunami phase. This discrepancy is larger when the earthquake loading induces high levels of non-linearity in the structure and when the tsunami intensity is low. Despite this, the shear internal force on the most critical column of the case-study building is reasonably well predicted. Finally, Section 4.4 only shows a small effect of FV or FC unloading analysis choice on the predicted structural response for the double pushover after the tsunami loading phase. As shear failure of ground storey columns is observed by [12] and [15] to define the initiation of collapse in reinforced concrete frame buildings under tsunami loading, the double pushover approach could be used for the derivation of collapse fragility functions of such structures subjected to earthquakes and tsunami in sequence. However, given the well-known limitations of earthquake pushover analyses [22], this approach would only be adequate in the case of low- to mid-rise buildings. Of the options tested, PO-FV-VDPO and PO-FC-VDPO outperform the others, and are the preferred analysis 
combination for the double pushover approach.

The choice of applied tsunami lateral load distribution is consistently seen to have a strong effect on predicted structural deformations under the earthquake and tsunami loading sequence, but an insignificant effect on the predicted internal shear on the critical column (1011). Hence, collapse prediction of the building is insensitive to this choice.

\section{THE EFFECT OF THE EARTHQUAKE ON TSUNAMI RESPONSE AND SENSITIVITY TO ANALYSIS TYPE}

In this section, we look more closely at the effect of the preceding earthquake on the post-earthquake tsunami capacity, and how this predicted residual structural capacity is affected by the choice of analysis type. To carry out this investigation, DY-FV-VDPO is adopted as the new reference case. The 16 earthquake ground motions presented in of Section 3.2 are used to run DY-FV-VDPO analyses, and the effect of the earthquake on the tsunami capacity of the case-study building is assessed in terms of $F_{T R \max }$, which is defined as the peak base shear attained in the tsunami VDPO, and the shear internal force over the most loaded column (1011). Both response parameters are shown by [12] to play an important role in the collapse behaviour of a structure under tsunami-only, with ductility (and hence deformation) taking a secondary role in the tsunami driven response of structures [16].

The effects of choice of analysis method for the earthquake loading and the unloading phases are investigated by comparing DY-FV-VDPO with PO-FV-VDPO, PO-FC-VDPO, PO-FV-CDPO and PO-FC-CDPO. Figures 10a and $10 \mathrm{~b}$ show the results of the comparison when $F_{T R \max }$ is plotted against the maximum inter-storey drift $\left(I D R_{\max }\right.$, $D Y)$ and maximum roof drift $\left(\mathrm{RD}_{\max }, D Y\right)$ of the earthquake non-linear response analysis, respectively. Only combinations of analysis with VDPO are shown in the figures for clarity, but the analyses with CDPO follow the same trends shown. Both Figures 10a and 10b show that in the case of DY-FV-VDPO, (the new reference case), $F_{T R \text { max }}$ does not appreciably reduce with increasing EDPs in the earthquake phase. This is considered the most reliable combination of analysis methods, and these results effectively indicate that earthquake damage does not have a significant effect on the tsunami response of the building. Though this seems counter-intuitive, this is explained by the significant differences in loading pattern applied by the two hazards, and resulting different predominant mechanisms of failure in the case-study structure, i.e. flexure dominated in the case of earthquakes and shear dominated in the case of tsunami.

Instead, Figure $10 \mathrm{~b}$ shows a significant reduction in $F_{T R \max }$ with increasing $R D_{\max , D Y}$ when the earthquake pushover is used (e.g. up to a maximum of about $10 \%$ for PO-FC-CDPO and $15 \%$ for PO-FC-VDPO under the considered 16 earthquakes). Figure 10 a shows a less clear relationship between $I D R_{\max } D Y$, and $F_{T R} \max$ for the analysis combinations using PO, but shows that significant underestimation of $F_{T R \text { max }}$ can result in some of the earthquake cases.

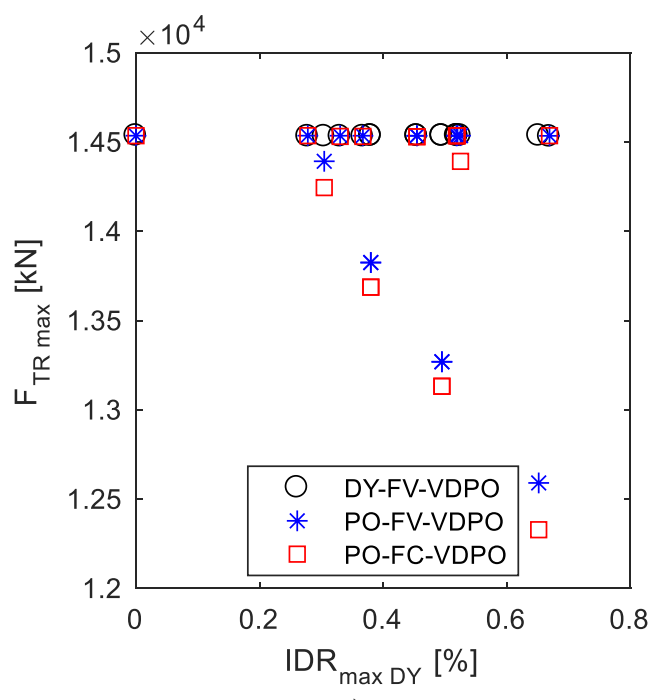

a)

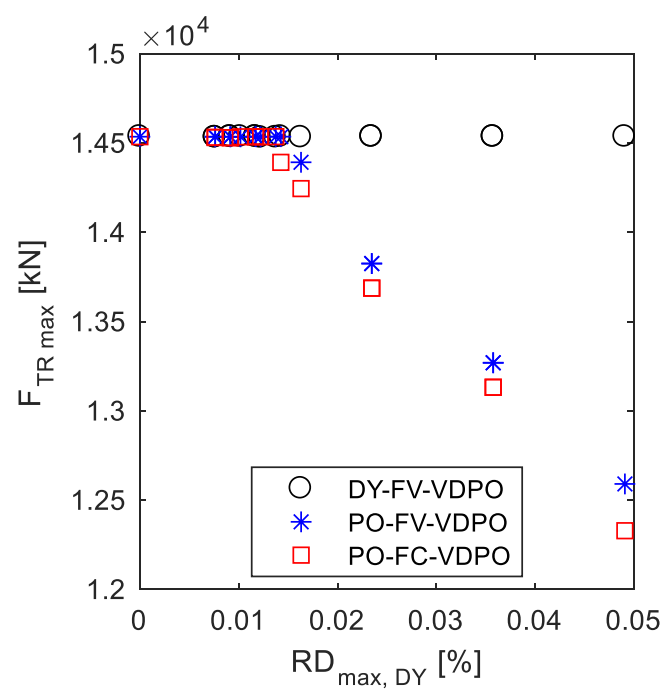

b) 


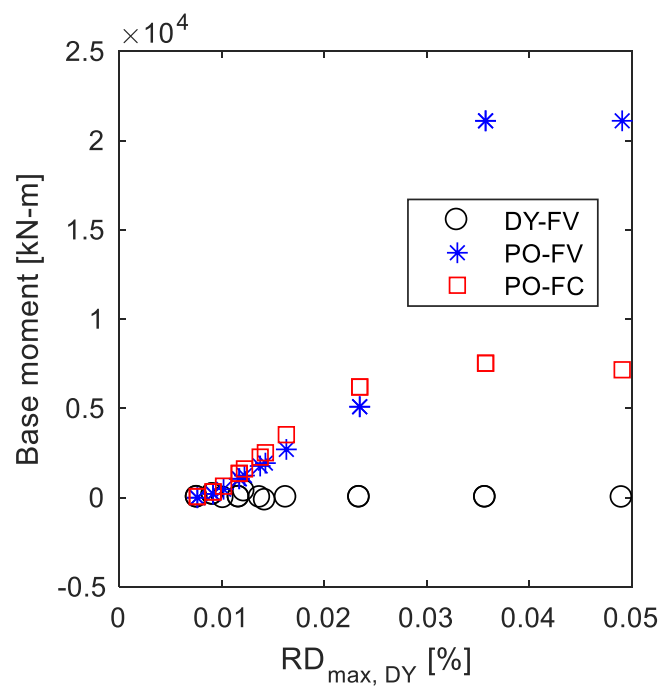

c)

Figure 10. Tsunami strength degradation and residual base moment after the earthquake excitation. (a) and (b): maximum strength for and VDPO $\left(h_{\max }=21 \mathrm{~m}\right)$ when compared to $I D R_{\max } D Y$ and $R D_{\max , D Y}$.

(c): residual base moment after unloading phase.

The reason for this reduction in strength becomes clear when examining Figure 11, which presents the PO-FCTPO curves for an arbitrary inundation height of $7 \mathrm{~m}$ in the case of CDPO, and for $h_{\max }=21 \mathrm{~m}$ in the case of VDPO (both with $F_{r}=0.6$ ). The figure shows the tsunami pushover results after the structure has been subjected to four earthquake ground motions with increasing intensities, with the base shear calculated as the sum of the horizontal shear forces at the column bases and the roof drift being the ratio of roof displacement to building height measured during the earthquake or tsunami analyses. The graphs show a progressive shift along the roof drift axis of the point at which the tsunami loading phase starts. This shift represents the residual displacement resulting from the earthquake pushover analysis and unloading phase, and increases as the earthquake pushover pushes the structure into the nonlinear range, sustaining permanent deformation. This permanent deformation effectively manifests itself as a tilt in the structure which induces a residual overturning moment at the structure base due to larger P- $\Delta$ effects (e.g. Figure 10c). The latter results in a reduced tsunami lateral capacity, which reduction is greater the larger the earthquake induced roof displacement.

When the unloading FC and FV cases are compared, it is also observed that FC results in slightly larger residual displacements than FV. This results in a slight difference in the $F_{T R} \max$ predicted by the methods (up to $1 \%$ for both CDPO and VDPO).

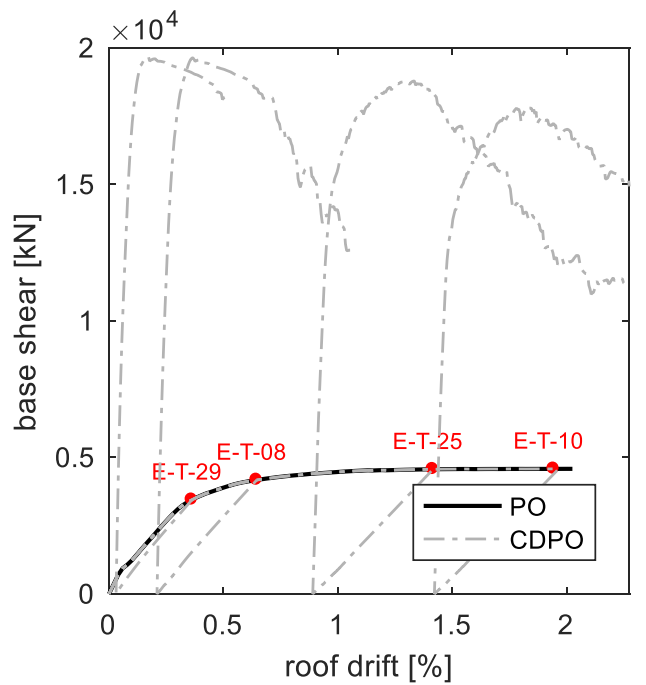

a)

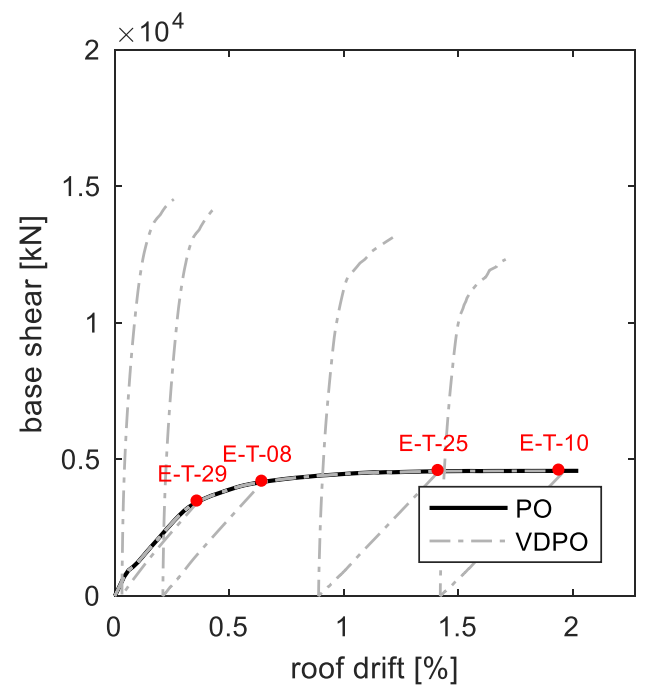

b)

Figure 11: Tsunami Strength degradation for: (a) PO-FC-CDPO with $h=7 \mathrm{~m}$, (b) PO-FC-VDPO with $h_{\max }=21 \mathrm{~m}$. Note that for clarity, only some selected earthquake records from the E-T pairs (as labelled) used in this paper have been plotted. 
This comparison shows that the predicted residual tsunami capacity, in terms of $F_{T R \max }$ is highly sensitive to the choices made for the earthquake loading phase analysis. However, despite the discrepancy in deformed shape and the difference in predicted global tsunami lateral strength, the shear internal force in column 1011 is estimated well by PO-FC-VDPO and PO-FC-CDPO when compared to the new reference DY-FV-VDPO case. This is consistent with the findings of Section 4.3. Furthermore, unlike the tsunami strength case, no apparent trend is observed in this case for increasing $R D_{\max , D Y}$ values. This means that the local shear internal force calculation is relatively insensitive to earthquake analysis type.

For the case study building, it is evident that the use of PO in the sequential earthquake and tsunami structural response assessment has a significant effect on the overall response. The ability of PO to be used in the context of building assessment for sequential earthquake and tsunami loads, is strongly affected by the discrepancy in residual displacements predicted by the earthquake pushover (PO) analysis versus earthquake response history analyses (DY). These discrepancies in residual deformation arise from (1) differences in deformed shape of the case study structure under the corresponding imposed earthquake loads, and (2) the assumptions made when determining the point at which to stop the earthquake pushover (as discussed in Section 3.3). Indeed, given the observations made, PO analysis would not be recommended for a detailed response analysis of this structure.

\section{CONCLUSIONS}

This paper presents a comprehensive study of how the assessment of structural response under sequential earthquake and tsunami loading is affected by the selection of different analysis methods in each of the three phases of assessment (earthquake loading, unloading and tsunami loading). A comparison is made between the overall response predicted by the fully dynamic case (DY-FV-TDY combination), that considered the most accurate case, and a number of combinations of analysis approaches of diminishing computational effort. Despite the fact that several assumptions have been made in the study and that a single case study has been used, the following general conclusions can be drawn with some level of confidence:

- When compared with the fully dynamic case, DY-FV-TPO methods present excellent predictions in terms of global behaviour, inter-storey drift (IDR) responses and shear internal forces over the critical elements. This is particularly true for the DY-FV-VDPO combination, which proves to achieve better agreements in the results, when compared with DY-FV-CDPO.

- Earthquake damage may not have a significant effect on the tsunami strength of a seismically designed buildings, if the earthquake induced damage is relatively small. This is explained by the significant differences in loading pattern applied by the two hazards, and resulting different predominant mechanisms of failure, i.e. flexure dominated in the case of earthquakes and shear dominated in the case of tsunami. The earthquake damage may, however, have a significant effect on the structure deformation under tsunami loading.

- The proposed double pushover approach, and in particular the PO-FV-VDPO analysis combination, yields a reasonable estimate of the shear forces over the structural elements that are critical to the tsunami response of the structure (e.g. base column facing the loading). However, the double pushover may present considerable bias in terms of assessing the IDR ratios of the structure after the tsunami impact and in the tsunami lateral strength. The latter two have been proven to be significantly influenced by the determination of the earthquake performance point (i.e. where to stop the earthquake pushover phase).

These observations suggest the following recommendations for the analysis of buildings under sequential earthquake and tsunami hazards:

- For critical infrastructure and irregular and/or tall structures, a nonlinear response history analysis for the earthquake loading phase, followed by a free vibration unloading and Variable Depth Pushover analysis for the tsunami loading (DY-FV-VDPO) provides an appropriate balance between accuracy and computational expense. An advantage of using this combination instead of the more complex DY-FVTDY methodology, is that the analysed structure can be assessed under a number of tsunami inundation severities without the need to obtain tsunami inundation time histories for the location of the assessed infrastructure.

- For the assessment of regular structures with first-mode dominated response under earthquake loading, (i.e. where PO is expected to well-represent the earthquake building performance), the double pushover approach (e.g. PO-FC-VDPO) can provide a viable alternative, being significantly simpler to implement and requiring a much reduced computational effort. In particular, the double pushover method may be suitable for use in the collapse fragility assessment of classes of such buildings, where a significant saving in computational expense might justify the loss in accuracy of response prediction.

Confirmation of these recommendations requires a repetition of the study to be carried out on a number of different 
structure types. Further work is needed to determine the influence on the predicted final response of using a capacity spectrum-based approach to assess the earthquake performance in the earthquake loading phase. Additionally, only traditional earthquake pushover approaches have been considered, and the use of an adaptive pushover approach warrants further investigation. Finally, significant limitations of the work presented in this paper are related to the tsunami loading representation. Among these, are the neglect of impulsive forces, debrisrelated forces and buoyancy forces on the structural tsunami response. The inclusion of these requires further investigation.

\section{ACKNOWLEDGEMENTS}

The research presented in this paper has been predominantly funded by the European Research Council under the European Union's Seventh Framework Programme (FP7/2007-2013)/ERC grant agreement number 336084 'URBANWAVES', awarded to Professor Tiziana Rossetto. We thank Willis Re for supporting the time of Dr. Petrone for this research.

\section{REFERENCES}

1. Fraser S, Raby A, Pomonis A, Goda K, Chian SC, Macabuag J, Offord M, Saito K, Sammonds P. Tsunami damage to coastal defences and buildings in the March 11th 2011 Mw9.0 Great East Japan earthquake and tsunami. Bulletin of Earthquake Engineering 2012; 11(1): 205-239.

2. Kajitani Y, Chang SE, Tatano H. Economic impacts of the 2011 Tohoku-Oki earthquake and tsunami. Earthquake Spectra 2013; 29(SUPPL.1): S457-S478.

3. Palermo D, Nistor I, Saatcioglu M, Ghobarah A. Impact and damage to structures during the 27 February 2010 Chile tsunami. Canadian Journal of Civil Engineering 2013; 40(8): 750-758.

4. Goda K, Petrone C, de Risi R, Rossetto T. Stochastic coupled simulation of strong motion and tsunami for the 2011 Tohoku, Japan earthquake. Stochastic Environmental Research and Risk Assessment 2017; 31(9): 2337-2355.

5. Suppasri A, Latcharote P, Bricker JD, Leelawat N, Hayashi A, Yamashita K, Makinoshima F, Roeber V, Imamura F. Improvement of tsunami countermeasures based on lessons from the 2011 Great East Japan Earthquake and Tsunami - Situation after five years. Coastal Engineering Journal 2016; 58(4): 1640011.

6. Mas E, Koshimura S, Suppasri A, Matsuoka M, Matsuyama M, Yoshii T, Jimenez C, Yamazaki F, Imamura F. Developing tsunami fragility curves using remote sensing and survey data of the 2010 Chilean Tsunami in Dichato. Natural Hazards and Earth System Science 2012; 12(8): 2689-2697.

7. Suppasri A, Mas E, Charvet I, Gunasekera R, Imai K, Fukutani Y, Abe Y, Imamura F. Building damage characteristics based on surveyed data and fragility curves of the 2011 Great East Japan tsunami. Natural Hazards 2013; 66(2): 319-341.

8. Charvet I, Ioannou I, Rossetto T, Suppasri A, Imamura F. Empirical fragility assessment of buildings affected by the 2011 Great East Japan tsunami using improved statistical models. Natural Hazards 2014; 73(2): 951-973.

9. Charvet I, Macabuag J, Rossetto T. Estimating tsunami-induced building damage through fragility functions: Critical review and research needs. Frontiers in Built Environment 2017; 3(36).

10. Qi ZX, Eames I, Johnson ER. Force acting on a square cylinder fixed in a free-surface channel flow. Journal of Fluid Mechanics 2014; 756: 716-727.

11. Foster ASJ, Rossetto T, Allsop W. An experimentally validated approach for evaluating tsunami inundation forces on rectangular buildings. Coastal Engineering 2017; 128(2017): 44-57.

12. Petrone C, Rossetto T, Goda K. Fragility assessment of a RC structure under tsunami actions via nonlinear static and dynamic analyses. Engineering Structures 2017; 136: 36-53.

13. Macabuag J, Rossetto T, Lloyd T. Structural analysis for the generation of analytical tsunami fragility functions. 10th Internation Conference on Urban Earthquake Engineering 2014.

14. Attary N, van de Lindt JW, Unnikrishnan VU, Barbosa AR, Cox DT. Methodology for development of physics-based tsunami fragilities. Journal of Structural Engineering 2017; 143(5).

15. Alam MS, Barbosa AR, Scott MH, Cox DT, van de Lindt JW. Development of physics-based tsunami fragility functions considering structural member failures. Journal of Structural Engineering 2017; 44(3): 04017221.

16. Rossetto T, Petrone C, Eames I, De La Barra C, Foster A, Macabuag J. Advances in the assessment of buildings subjected to earthquakes and tsunami. In: Recent Advances in Earthquake Engineering in Europe: 16th European Conference on Earthquake Engineering-Thessaloniki 2018. Springer International Publishing: 2018. 545-562.

17. ASCE/SEI 7-16. Minimum design loads for buildings and other structures. Chapter 6: Tsunami loads and effects. Reston, VA: ASCE/SEI: 2016. 
18. Park S, van de Lindt JW, Cox D, Gupta R, Aguiniga F. Successive earthquake-tsunami analysis to develop collapse fragilities. Journal of Earthquake Engineering 2012; 16(6): 851-863.

19. Folz B, Filiatrault A. Cyclic analysis of wood shear walls. Journal of Structural Engineering 2001; 127(4): 433-441.

20. Applied Technology Council. FEMA P646. Guidelines for Design of Structures for Vertical Evacuation from Tsunamis. Redwood City (CA): 2008.

21. Latcharote P, Kai Y. Nonlinear structural analysis of reinforced concrete buildings suffering damage from earthquake and subsequent tsunami. 10th U.S. National Conference on Earthquake Engineering Frontiers of Earthquake Engineering, 2014.

22. D'Ayala D, Meslem A, Vamvatsikos D, Porter K, Rossetto T. Guidelines for analytical vulnerability assessment of low/mid-rise buildings. Vulnerability Global Component Project. Vol. 8. 2015.

23. Rossetto T, Gehl P, Minas S, Galasso C, Duffour P, Douglas J, Cooke O. FRACAS: A capacity spectrum approach for seismic fragility assessment including record-to-record variability. Engineering Structures 2016; 125: 337-348.

24. Michel C, Crowley H, Hannewald P, Lestuzzi P, Fäh D. Deriving fragility functions from bilinearized capacity curves for earthquake scenario modelling using the conditional spectrum. Bulletin of Earthquake Engineering 2018: 1-22.

25. FEMA. FEMA 356. Prestandard and Commentary for the Seismic Rehabilitation of Buildings. Washington: 2000.

26. Deierlein GG, Reinhorn AM, Willford MR. Nonlinear structural analysis for seismic design: A guide for practicing engineers. NEHRP Seismic design technical brief no. 4. Gaithersburg (MD): 2010.

27. Bazzurro P, Cornell A, Menun C, Motahar M. Guidelines for seismic assessment of damaged buildings. 13th World Conference on Earthquake Engineering, Vancouver B.C.: 2004.

28. McKenna F, Fenves G. OpenSees Manual. Berkeley, California: 2013.

29. Chopra AK, Chopra AK. Dynamics of structures: theory and applications to earthquake engineering. Vol.3. Upper Saddle River, NJ:pearson/Prentice-Hall; 2007.

30. Macabuag J, Rossetto T, Ioannou I, Suppasri A, Sugawara D, Adriano B, Imamura F, Eames I, Koshimura S. A proposed methodology for deriving tsunami fragility functions for buildings using optimum intensity measures. Natural Hazards 2016: 84(2):1257-1285.

\section{APPENDIX}

Table summarises the characteristics of the earthquake-tsunami pairs used in this study. All the ground motion records have a duration of $140 \mathrm{~s}$.

Table 2. Earthquake-tsunami pairs used in this study.

\begin{tabular}{|c|c|c|c|c|c|c|c|}
\hline E-T pair ID & PGA (g) & $\mathbf{S a}(\mathbf{0 . 7 3} \mathbf{~ s})$ & $\mathbf{F}_{\mathbf{T}}(\mathbf{k N})$ & $\mathbf{h}^{\text {peak }} \mathbf{a t} \mathbf{F}_{\mathbf{T}}(\mathbf{m})$ & $\mathbf{u} \mathbf{a t} \mathbf{F}_{\mathbf{T}}(\mathbf{m} / \mathbf{s})$ & $\mathbf{F r}^{\text {peak }} \mathbf{a t ~}_{\mathbf{T}}$ & $\begin{array}{c}\text { Tsunami } \\
\text { duration }(\mathbf{s})\end{array}$ \\
\hline E-T-01 & 0.433 & 0.609 & 734.930 & 2.460 & -4.330 & 0.882 & 425 \\
\hline E-T-05 & 0.552 & 0.457 & 4122.164 & 5.760 & -6.740 & 0.897 & 597 \\
\hline E-T-08 & 0.952 & 0.344 & 466.303 & 3.250 & -2.330 & 0.413 & 362.5 \\
\hline E-T-15 & 0.806 & 0.298 & 3071.122 & 11.220 & -3.180 & 0.303 & 372 \\
\hline E-T-19 & 0.250 & 0.609 & 7467.409 & 8.660 & -7.000 & 0.760 & 205 \\
\hline E-T-21 & 0.321 & 0.572 & 6410.927 & 8.820 & -6.130 & 0.659 & 229 \\
\hline E-T-11 & 0.274 & 0.617 & 2373.426 & 5.280 & -4.860 & 0.675 & 630.5 \\
\hline E-T-17 & 0.806 & 0.298 & 7538.810 & 9.510 & -6.420 & 0.665 & 473 \\
\hline E-T-20 & 0.552 & 0.457 & 7586.031 & 9.280 & -6.610 & 0.693 & 261.5 \\
\hline E-T-23 & 1.130 & 0.340 & 7386.874 & 11.790 & -5.100 & 0.474 & 617 \\
\hline E-T-25 & 1.130 & 0.340 & 1646.138 & 7.170 & -2.720 & 0.324 & 471 \\
\hline E-T-10 & 0.632 & 0.502 & 2192.915 & 5.410 & -4.470 & 0.614 & 422.5 \\
\hline E-T-02 & 0.559 & 0.468 & 523.300 & 2.780 & -2.970 & 0.569 & 583.5 \\
\hline E-T-27 & 0.694 & 0.360 & 12501.695 & 13.140 & -6.790 & 0.598 & 529.5 \\
\hline E-T-28 & 0.916 & 0.298 & 11310.648 & 12.030 & -6.880 & 0.633 & 446.5 \\
\hline E-T-29 & 0.250 & 0.609 & 10437.033 & 12.650 & -6.160 & 0.553 & 201 \\
\hline
\end{tabular}

